\title{
CMIP3 ensemble climate projections over the western tropical Pacific based on model skill
}

\author{
Sarah E. Perkins ${ }^{1,2,3, *}$, Damien B. Irving ${ }^{1,2}$, Josephine R. Brown ${ }^{2,3}$, Scott B. Power ${ }^{2,3}$, \\ Aurel F. Moise ${ }^{2,3}$, Robert A. Colman ${ }^{2,3}$, Ian Smith ${ }^{2,3}$ \\ ${ }^{1}$ Centre for Australian Weather and Climate Research, CSIRO Marine and Atmospheric Research, Aspendale, Victoria 3195, \\ Australia \\ ${ }^{2}$ Centre for Australian Weather and Climate Research, Bureau of Meteorology, GPO Box 1289, Melbourne, Victoria 3001, \\ Australia \\ ${ }^{3}$ Present address: ARC Centre of Excellence for Climate System Science, The University of New South Wales, Sydney, \\ NSW 2052 Australia
}

\begin{abstract}
Climate projections provide important information for risk assessment and adaptation planning. The CMIP3 archive of global climate model (GCM) simulations has been used extensively for such projections over land-based regions, but limited attention has been paid to the western tropical Pacific, where vulnerability is likely to be high. Adaptation policies within the western Pacific currently are based on the heavily summarised information within the IPCC fourth assessment report. This study builds upon the IPCC projections by analysing and presenting projections of change from the CMIP3 GCMs and demonstrating spatial differences in projections across the west Pacific domain. Atmospheric fields considered in this paper include surface air temperature, precipitation, and wind speed and direction for the SRES A2 emission scenario for 2080-2099, where the projected change is relative to 1980-1999. Results for all fields are based on 3 types of multi-model ensembles: the all-model (ALL) ensemble (19 models), the BEST ensemble (15 models) and the WORST ensemble (4 models). The BEST and WORST ensembles are based on model skill in simulating relevant climatic features, drivers and variables, which govern the interannual and annual climate of the study region. The WORST ensemble was found to generally exhibit a statistically significant bias in projections for precipitation, wind speed and wind direction in reference to the ALL ensemble. This bias is always statistically significantly different for surface air temperature. Some biases are still present in the BEST ensemble for all variables in comparison to the ALL ensemble, and uncertainty is not always reduced when the WORST models are eliminated from the ensemble. Overall, we advocate the use of the BEST ensemble when considering domain-wide projections due to the ability of the model members to simulate the current climate across the region.
\end{abstract}

KEY WORDS: CMIP3 climate models $\cdot$ Ensembles $\cdot$ Pacific region $\cdot$ Climate projections

\section{INTRODUCTION}

Christensen et al. (2007) broadly outline temperature and precipitation projections over the Pacific region, using an ensemble of simulations from global climate models (GCMs) from the Intergovernmental Panel on Climate Change (IPCC) 4th Assessment Report (AR4) archive (now known as Phase 3 of the World Climate Research Project Cli- mate Model Intercomparison Project, CMIP3; Meehl et al. 2007a). Through an assessment of the current climate literature, the AR4 reported that across most of the Pacific region, temperature projections tend to follow the global average warming rate, although stronger warming occurs in the central equatorial Pacific and weaker warming occurs in the south. The strongest increases in precipitation occur over the Intertropical Convergence Zone 
(ITCZ; Christensen et al. 2007, see also Meehl et al. 2007b).

Most island states within the Pacific have a low adaptive capacity to climate variability and change, especially for extreme weather events (Mimura et al. 2007, Nunn 2009). Furthermore, the magnitude of projected changes in a given variable or process may result in amplified impacts. For example, a $10 \%$ reduction in precipitation by 2050 could lead to a $20 \%$ reduction of the freshwater lens on Tarawa Atoll, Kiribati (Mimura et al. 2007). Other impacts include those on agriculture and human health which are directly related to temperature and precipitation changes, as well as coastal impacts associated with sea level rise and storm surges (Mimura et al. 2007). The impacts of climate change on many of the Pacific islands may be further exacerbated by their remote location and small size (Nunn 2009).

The Asian Development Bank (ADB) Climate Change Implementation Plan for the Pacific (ADB 2009) is used extensively by the Pacific Islands as a reference in adaptation and mitigation planning. However, projection data listed in the report is outdated by more recent peer-reviewed literature. While a very valuable resource, recent research indicates that the ADB (2009) report under-estimates the range of sea-level rise (e.g. Lowe \& Gregory 2010) and over-states the current confidence in El NiñoSouthern Oscillation (ENSO) projections (e.g. Meehl et al. 2007a, Collins et al. 2010). Both the AR4 (Meehl et al. 2007b) and much of the current literature indicate that changes in the frequency and severity of El Niño and La Niña events are uncertain over the 21st century (e.g. Guilyardi et al. 2009, Collins et al. 2010). The ADB (2009) report also shows inconsistencies with the AR4 in temperature and precipitation projections, where changes for 2080-2099 are based on 21 GCMs for the A1B scenario for maximum, minimum and the 25th, 50th and 75th percentile changes over the north and south Pacific (Christensen et al. 2007, their Table 11.1). There is an urgent need to provide projections based on the latest climate models to the Pacific Islands to overcome such inconsistencies, as updated and improved projections have the potential to improve adaptation and mitigation planning.

The present study addresses this issue by developing projections for the western Pacific based on CMIP3 GCMs. Projections of change are provided for annual and 6-monthly (i.e. wet season/dry season) surface air temperature (TAS), precipitation (PR), wind speed (WSP) and wind direction (WDIR) over a spatial domain prescribed by the Pacific Climate Change Science Program (PCCSP; Fig. 1). The
PCCSP is an Australian research program aimed at improving the availability of climate science information for 15 developing countries (Palau, Federated States of Micronesia, Marshall Islands, Nauru, Kiribati, East Timor, Papua New Guinea, Solomon Islands, Vanuatu, Tuvalu, Fiji, Tonga, Samoa, Niue and the Cook Islands). Projections for each variable are analysed for the Special Report on Emission Scenarios (SRES) A2 (high emissions) scenario (Nakićenović et al. 2000), for the overall PCCSP domain (i.e. the area indicated in Fig. 1) as well as 3 feature-based regions. The feature-based regions are defined by the dominating climate features, the South Pacific Convergence Zone (SPCZ), the ITCZ, and the West Pacific Monsoon (WPM).

Before projections are derived from climate models, their 20th century simulations are compared with observations qualitatively and quantitatively. This assessment is very important since GCMs differ in their ability to simulate key climate variables due to differences in model resolution, parameterization schemes (Liu et al. 2010, Zhang \& Song 2010) and the representation of physical processes (e.g. the carbon cycle, dynamic vegetation, aerosol effects). Many studies (Murphy et al. 2004, Dessai et al. 2005, Piani et al. 2005, Perkins et al. 2007, Gleckler et al. 2008, Pierce et al. 2009, Reifen \& Toumi 2009, Santer et al. 2009, Smith \& Chandler 2010, Brown et al. 2011, Irving et al. 2011) have documented the skill of the CMIP3 GCMs for a range of variables and processes using a suite of metrics for various spatial domains. Collectively, these studies have shown that a given model's skill may vary across different climatic fields and regions. Gleckler et al. (2008) concluded that no CMIP3 model performs 'best' for every simulated variable, nor is any one model above average for all variables. Irving et al. (2011) and Brown et al. (2011) further demonstrated this for the PCCSP domain. There is evidence that the all-model ensemble (consisting of all models with available data), where all models are uniformly weighted (i.e. the all-model ensemble average), performs better than any single GCM, despite the individual model's performance (Tebaldi \& Knutti 2007, Reifen \& Toumi 2009, Santer et al. 2009). However there is also evidence, at least at the regional scale, that rejecting models which perform poorly over multiple criteria may narrow the uncertainty and range in future projections (Perkins et al. 2009, Sánchez et al. 2009, Knutti et al. 2010).

The approach taken in this paper therefore attempts to combine findings and guidelines by studies such as Tebaldi \& Knutti (2007), Stainforth et al. (2007), Perkins et al. (2009), Knutti et al. (2010) and 


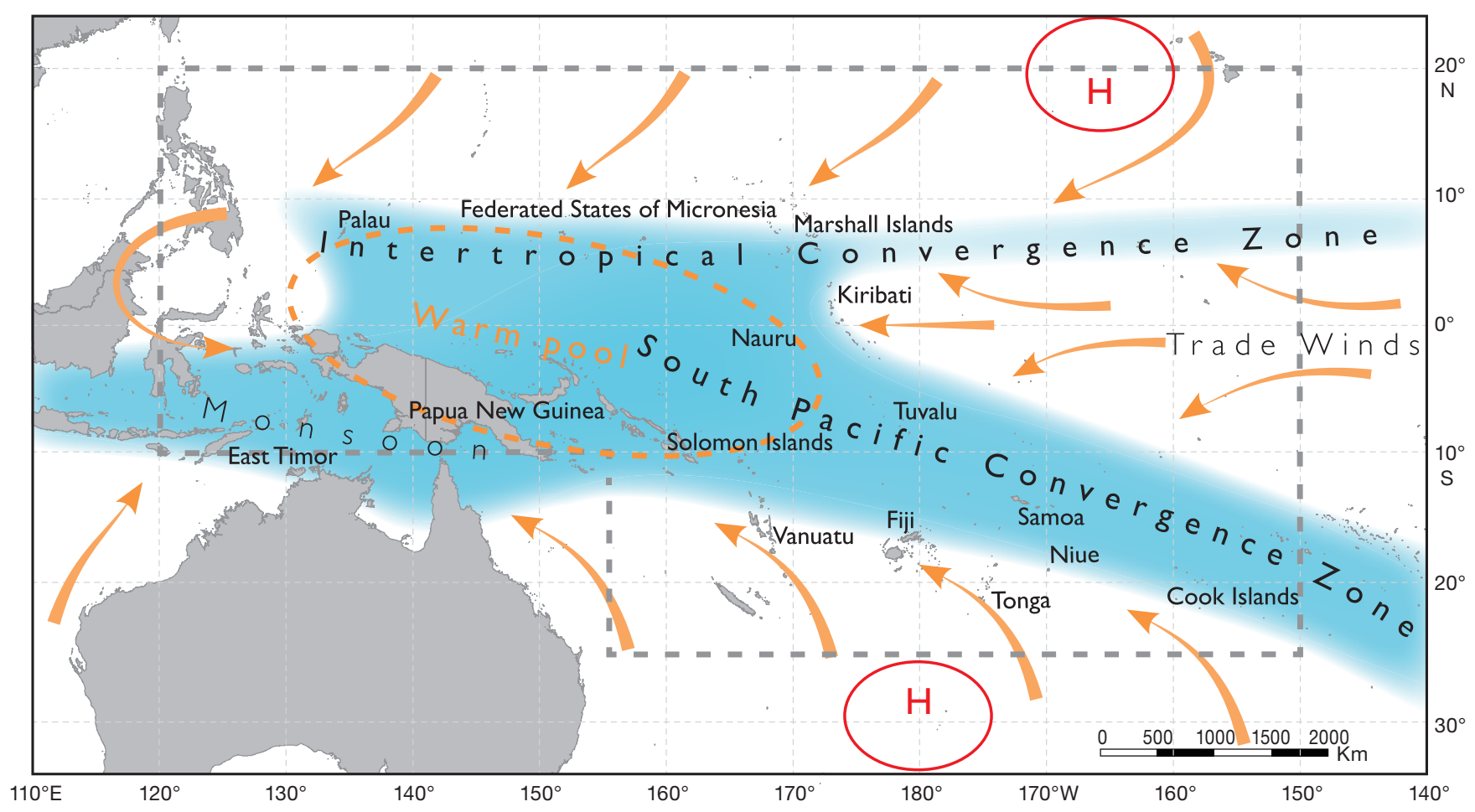

Fig. 1. Locations of the Pacific Climate Change Science Program (PCCSP) partner countries (all of which are labelled) and the dominant features of the regional climate in the western Pacific Ocean. Grey dashed lines indicate the boundary of the 'PCCSP region' used in much of the analysis, and orange arrows indicate the dominant wind flows

Smith \& Chandler (2010). This incorporates a multimodel ensemble (MME) across most models, where models believed to be missing or strongly distorting key processes are disregarded (Irving et al. 2011). The exclusion of such models has been shown to produce projections which are different to all-model ensemble projections (Perkins et al. 2009). We adopt this approach here using the extensive regional assessment of CMIP3 GCMs by Irving et al. (2011) in an attempt to reduce some of the uncertainty in future projections. The GCMs that are eliminated in this study were shown by Irving et al. (2011) to be demonstrably weak in simulating a number of important aspects of tropical Pacific climate.

While some models left in the MME may still be considered 'outliers' in their current and/or future projections (e.g. their individual projections deviate greatly from the MME mean), they are retained because they demonstrated reasonable skill in simulating the current climate and higher skill than the models excluded. The issue of weighting models based on their skill in simulating observed climate has been the subject of much discussion if equal weighting is sufficient (e.g. Giorgi \& Mearns 2002, 2003, Murphy et al. 2004, Tebaldi et al. 2006, Räisänen 2007, Stainforth et al. 2007, Perkins \& Pitman 2009, Sánchez et al. 2009, Xu et al. 2010). Weigel et al. (2010) constructed a framework which illustrated that in theory, projection errors within an MME can be reduced when participating models are assigned an optimum weighting. However, we stress that constructing optimum weights requires very accurate knowledge of model skill, of which there is no consensus as to what such measures constitute. Taking this into consideration, Weigel et al. (2010) further show that an incorrectly weighted MME performs on average worse than a uniformly weighted MME and therefore advocate a uniform weighting as a transparent method which will generally obtain optimum results. This framework, combined with removing the weakest models, is also supported by Räisänen (2007) and Stainforth et al. (2007).

Furthermore, by eliminating the models with lower skill outlined by Irving et al. (2011), we have attempted to reduce some of the uncertainty in future projections (Knutti et al. 2010). Uncertainties in climate projections come from various sources (e.g. Schneider et al. 2002), and quantifying, as well as reducing, these uncertainties is beyond the scope of this paper. Some aspects of uncertainty not addressed here are the focus of the IPCC 5th assessment report process. Here we eliminate the least skilful models 
and assign equal weight to the models retained.

The remainder of this paper is as follows. Section 2 describes the data and methods used in this study, followed by a summary of how the main climate features and drivers of the study region are evaluated in the CMIP3 GCMs. Section 3 provides the results, Section 4 a discussion including linking changes in variables to changes in climate drivers and features and Section 5 a summary and conclusions.

\section{DATA AND METHODS}

\subsection{Study region and model data}

The spatial domain of the study region considered is shown in Fig. 1, with latitude bounds of $25^{\circ} \mathrm{S}$ to $20^{\circ} \mathrm{N}$ and longitude bounds of $120^{\circ} \mathrm{E}$ to $210^{\circ} \mathrm{E}$, i.e. $150^{\circ} \mathrm{W}$. The domain was chosen because it incorporates all partner countries of the PCCSP: Palau, Federated States of Micronesia, Marshall Islands, Nauru, Kiribati, East Timor, Papua New Guinea, Solomon Islands, Vanuatu, Tuvalu, Fiji, Tonga, Samoa, Niue and the Cook Islands. While these boundaries also include other countries, projections for these countries are not discussed in this study.

GCM data were obtained from the CMIP3 data archive from the Program for Climate Model Diagnosis and Intercomparison (PCMDI) at Lawrence Livermore National Laboratory (wwwpcmdi.llnl.gov/). A total of 19 out of 24 GCMs archived data for the A2 scenario, which are listed with their affiliations in Table 1. Atmospheric surface resolution among the CMIP3 GCMs ranges from $\sim 2^{\circ}$ $\times 2^{\circ}$ (e.g. CSIRO-Mk3.0) to $4^{\circ} \times 5^{\circ}$ (e.g. GISS-ER), so all models were regridded to $2.5^{\circ} \times 2.5^{\circ}$ using the SCRIP regridder within the Climate Data Analysis Tool (CDAT; www2-pcmdi.llnl.gov/cdat), allowing for the construction of multi-model ensembles. Projections for the 21st century are constructed for TAS, PR, WSP and WDIR for the SRES A2 emission scenario (Nakićenović et al. 2000) for the period 2080-2099 (henceforth called 2090) relative to
1980-1999 (taken from the 20c3m simulation). WSP and WDIR data were not available under the A2 scenario for 3 of the models (Table 1). This base period was chosen as it represents a climatology of the same length as the future period, is exactly one century earlier, and is included in the time period used to perform much of the evaluation in Irving et al. (2011), where models are compared to 'current' conditions. The choice of this period for evaluation in Irving et al. (2011) was determined by the length and quality of data of the reference products, particularly when considering the inclusion of satellite data in 1979. Annual and 6-monthly projections encompassing May to October (MJJASO) and November to April (NDJFMA) are considered for all variables. For consistency, only the first run from each model was used. 


\subsection{Model evaluation and selection}

To potentially reduce some of the uncertainty in projections, this study uses the results of Irving et al. (2011), where the CMIP3 GCMs were evaluated rigorously over the PCCSP region (see Fig. 1). Generally, the evaluation of a climate model includes comparing the 20th century model output to observations/ reanalyses over the same time period. This assumes that a model's performance in simulating the current climate will influence its ability to simulate future conditions. While there is no guarantee that this assumption will be met (Jun et al. 2008, Knutti 2010), evaluating a model for events that have not yet occurred is impossible. However, they can be investigated if models which perform well in simulating the current climate (i.e. members of the BEST ensemble, see Section 2.3) converge in their future projections. This has been addressed in other regional studies (e.g. Perkins \& Pitman 2009, Perkins et al. 2009) and is a major focus of the current study.

Irving et al. (2011) evaluated the CMIP3 GCMs for their ability to simulate 9 key aspects of 20th century climate. This list includes: TAS, WSP, WDIR, and PR; the dominating climate features including the SPCZ (Vincent 1994, Folland et al. 2002), ITCZ (Waliser \& Gautier 1993), and WPM (Hendon \& Liebmann 1990a,b); ENSO (Diaz \& Markgraf 2000, van Oldenborgh et al. 2005); the magnitude of spurious climate model drift (Power 1995, Covey et al. 2006); and sea surface temperature (SST) trends. For atmospheric (oceanic) evaluation, models were interpolated to a common $2.5^{\circ}\left(1.0^{\circ}\right)$ latitude/longitude grid prior to analysis. A brief description of how each aspect was evaluated is given below, and detail is presented in Irving et al. (2011).

For each of PR, TAS, WSP and WDIR, metrics used to assess each climate model include the phase and amplitude of the seasonal cycle. Over the period 1979-1999 Irving et al. (2011) assessed the ability of the models to simulate the:

(1) magnitude of temporal variability associated with the annual cycle;

(2) magnitude of temporal variability about the annual cycle;

(3) amplitude of spatial contrasts in climatological averages; and

(4) spatial structure of climatological averages.

In evaluating the ability of the CMIP3 climate models to simulate a realistic SPCZ, Irving et al. (2011) used the SPCZ region $\left(0\right.$ to $30^{\circ} \mathrm{S}$ and $155^{\circ} \mathrm{E}$ to $140^{\circ} \mathrm{W}$ ) of Brown et al. (2011). The mean location of the SPCZ over this region was assessed by calculat- ing the spatial correlation between the modeled and observed December to February (DJF) mean PR fields. Irving et al. (2011) also assessed the ability of the models to simulate interannual variability in the mean latitude of the SPCZ. The correlation between the mean SPCZ latitude and model Niño 3.4 index was calculated and compared with the observed relationship (see Brown et al. 2011 for details).

The mean location of the WPM was assessed by calculating the pattern correlation between the modeled and observed DJF PR over an appropriate WPM region $\left(20^{\circ} \mathrm{S}\right.$ to $20^{\circ} \mathrm{N}$ and $110^{\circ}$ to $\left.160^{\circ} \mathrm{E}\right)$. The intensity of the WPM has a strongly inverse relationship with ENSO (e.g. Zhu \& Chen 2002). Therefore, the ability of the models to simulate this relationship was assessed by calculating the correlation between the total DJF PR over the WPM region and the model simulated Niño 3.4 index.

Interannual climate variability in the Pacific and surrounding regions is dominated by ENSO. In order to simulate a reasonable ENSO simulation, climate models need to realistically reproduce the (1) strength and frequency of ENSO events, (2) spatial pattern of ENSO, and (3) link between ENSO and climate variables such as PR. Property 1 was assessed by calculating the ratio between the standard deviation of modeled and observed monthly Niño 3.4 index variability over the period 1950-1999. Property 2 was assessed using the spatial correlation coefficient between modeled and observed maps of the temporal correlation between mean July to December Niño 3.4 index and the mean SST anomaly at each grid point over an 'ENSO region' $\left(25^{\circ} \mathrm{S}\right.$ to $25^{\circ} \mathrm{N}$ and $120^{\circ}$ to $240^{\circ} \mathrm{E}$ [i.e. $\left.\left.120^{\circ} \mathrm{W}\right]\right)$. Property 3 was assessed as follows. First the temporal variability in the July to December Niño 3.4 index was correlated with temporal variability in July to December PR totals at each grid point for both the models and the observations. The spatial correlation coefficient between the observational map and the corresponding map for each model was then calculated. The ratio between the standard deviation of the model and observed temporal correlation fields was also calculated and combined with it as per the $S$ statistic proposed by Taylor (2001).

A persistent problem with some coupled climate models is that of spurious climate drift, which is a drift in model climatology that is due to systematic errors in the climate model and not due to genuine climate variability or genuine external climate forcing (e.g. Power 1995, Covey et al. 2006, Sen Gupta et al. in press). These drifts are a result of errors in surface fluxes between the climate model components and deficiencies in the model physics, which mean 
that the equilibrium state of the model is different from the initial (usually observationally derived) state. In order to objectively evaluate spurious climate drift in each of the models, the magnitude of the pre-industrial (PIcntrl) linear TAS and PR trend at each grid point over the PCCSP region was calculated for a 150 yr period, aligning with the 1900-2050 period of the 20th century $(20 \mathrm{c} 3 \mathrm{~m})$ simulation. The spatial average of these trend magnitudes was taken as a measure of model drift. The method used to accomplish this is described by Sen Gupta et al. (in press).

The ability of the CMIP3 models to capture the warming observed in recent decades was assessed by calculating the 1950-1999 linear SST trends, using the 20c3m simulation at each grid point over the PCCSP region. These trends were corrected for spurious model drift by subtracting the linear trends from the 150 yr pre-industrial simulations and compared to observed trends by calculating the average magnitude of the grid point errors.

Once all of the above assessments were made, Irv- due to its large drift, GISS-ER as no ENSO signal is present, and PCM and INM-CM3.0 as they were found to be relatively poor performers over numerous metrics (Fig. 2). GISS-AOM and GISS-EH are also poor performers but do not provide data for the A2 scenario and are therefore not relevant to the present study.

\subsection{Model ensembles and projections}

Using the results of Irving et al. (2011), we define 3 ensembles to provide projections for each variable. These ensembles are (1) the ALL ensemble (all 19 models), (2) the BEST ensemble, which consists of BCCRBCM2.0, CCSM3, CGCM3.1(T47), CNRM-CM3, CSIRO-Mk3.0, CSIRO-Mk3.5, ECHAM5/MPI-OM, ECHO-G, GFDL-CM2.0, GFDL-CM2.1, IPSL-CM4, MIROC3.2 (medres), MRI-CGCM2.3.2, UKMOHadCM3, UKMO-HadGEM1, and (3) the WORST ensemble (INGV-SXG, GISS-ER, INM-CM3.0 and PCM only). Ensemble 2 (BEST) was calculated based ing et al. (2011) calculated a normalised score for each metric using a method similar to Santer et al. (2009), so that one metric per aspect (i.e. per variable, feature, ENSO and model drift) could be defined. Once the absolute error for each metric was obtained, it was normalised by converting it to an anomaly (i.e. by subtracting the multi-model average score) and then dividing that anomaly by the intermodel standard deviation. Good and poor performance was indicated by increasingly negative and positive normalised scores, respectively, and for each metric these normalised scores had a multi-model average of 0.0 and standard deviation of 1.0. To obtain an indication of overall model performance on each of the 9 key aspects, an average over all relevant normalized scores was also calculated by Irving et al. (2011) (Fig. 2).

The conclusions of Irving et al. (2011) therefore provide guidance on the relative skill of the models in simulating climate over the PCCSP region and which models to eliminate from particular projections. Models deemed as the poorest performers by Irving et al. (2011) include INGV-SXG

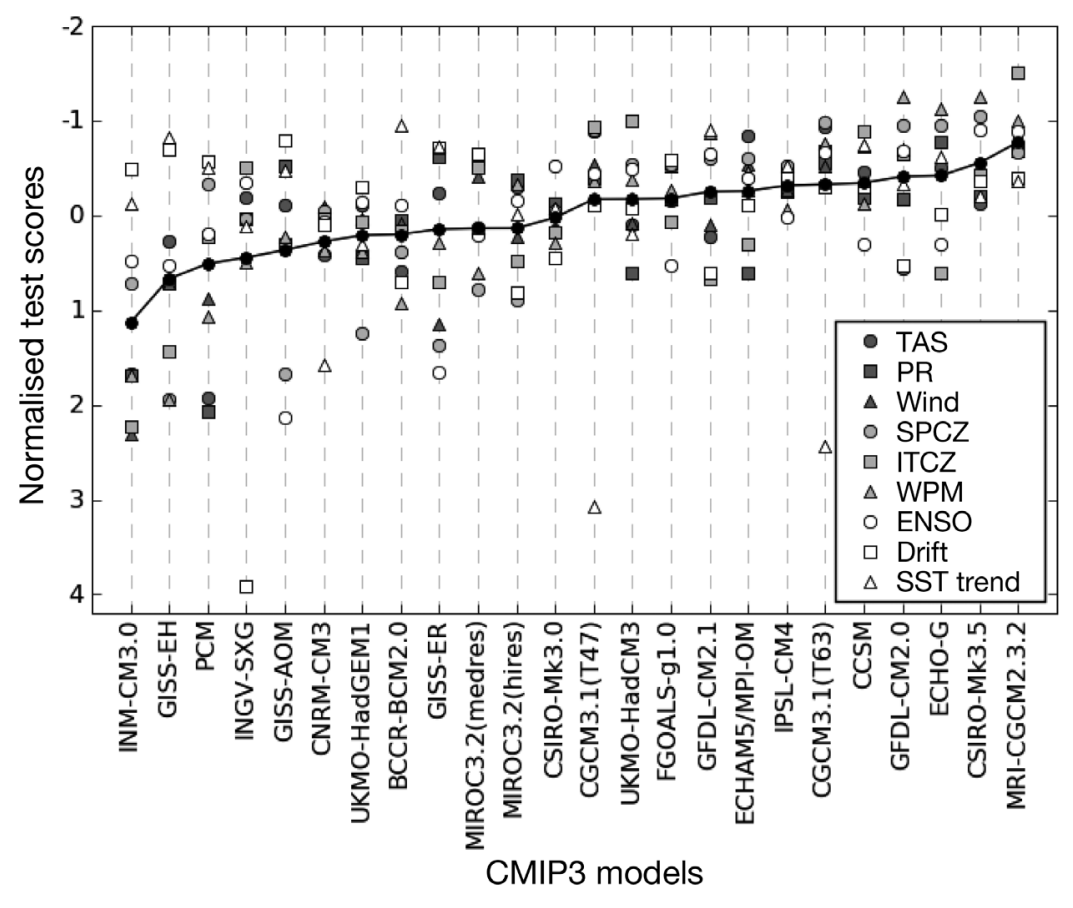

Fig. 2. Mean normalised test scores performed by Irving et al. (2011) for all 9 key aspects in each of the 19 CMIP3 climate model simulations (includes 5 models not used in this study: CGCM3.1(T63), GISS-EH, MIROC3.2hires, GISSAOM, FGOALS-g1.0). Increasing negative scores indicate better model performance. The connected solid black dots represent the average across all aspects. See Table 1 for model descriptions and Table 2 for region locations. Adapted from Fig. 8 of Irving et al. (2011). TAS: surface air temperature; PR: precipitation; SPCZ: South Pacific Convergence Zone; ITCZ: Intertropical Convergence Zone; WPM: West Pacific Monsoon; ENSO: El Niño-Southern Oscillation; SST: sea surface temperature 
on the performance of the GCMs across all criteria in Irving et al. (2011), where (INGV-SXG, GISS-ER, GISS-EH, INM-CM3.0 and PCM) were omitted from the ALL ensemble.

These 3 groups or ensembles of models were used for all annual and 6-monthly projections for all variables, that is the same models make up the BEST and WORST ensembles for each variable and time period. While there is strong evidence that any given model does not perform consistently across multiple variables (e.g. Whetton et al. 2007, Gleckler et al. 2008), segregation of the models into ensembles is based on the overall evaluation scores presented in Irving et al. (2011; our Fig. 2). Furthermore, using the same set of ensembles for all variables allows the present study to give physically consistent projections across a number of climate variables, unlike some previous regional studies (e.g. Pitman \& Perkins 2008, Perkins \& Pitman 2009).

Results in this paper are presented in a similar format to the IPCC AR4 (Meehl et al. 2007b, Christensen et al. 2007), showing mean projections of the ensembles and the corresponding standard deviations. Projections in the AR4 make use of all GCMs whereby taking the mean assigns equal weights to all members, or the 'one-model-one-vote' approach (Knutti 2010). As noted above, we take a similar approach in that all members of each of the 3 ensembles are equally weighted; however we include another step by constructing Ensembles 2 (BEST) and 3 (WORST) based on model skill, which allows us to determine if projections are altered by the elimination of certain models. The WORST ensemble is included to illustrate the influence that poorer performing models may have on the ALL ensemble; projections from this ensemble are not recommended for risk assessment and adaptation planning.

All projected changes are calculated individually for each model and the average is taken across all members of the respective ensembles. PR and WSP changes are calculated as percentages relative to the base period, TAS is presented in degrees Celsius and WDIR is presented as degrees change relative to the ensemble median base period direction (also shown). Positive values indicate a clockwise change, and negative values an anticlockwise change.

For each ensemble projection, the standard deviation $(\sigma)$ was calculated to measure intra-ensemble variability in order to quantify the contrasts between the individual members. Determining if the ensemble members have similar projections of change to one another is useful. In the case of the BEST ensemble, this can help determine if omitting the less- skilled models reduces some of the uncertainty by narrowing the spread of the projected changes, particularly when compared to the ALL ensemble. Furthermore, looking at a measure of spatial ensemble variability can help determine if the uncertainty associated with a given projection is uniform or if regional differences occur and if uncertainty differs across projection scenarios.

There are 15 models included in the BEST ensemble and only 4 in the WORST. This difference in ensemble size has an impact on $\sigma$. Conclusions by Irving et al. (2011) suggest only 6 models with little confidence in simulating the current climate from the overall CMIP3 ensemble of 24, of which a total of only 19 provide data for the A2 scenario. Based on the overall evaluation performed (Fig. 2), there is not enough evidence to remove any of the other 18 (15). Although some models have a wide range of performance across all aspects, their overall scores are similar, which makes it hard to distinguish between the models any further, resulting in only 4 models in the WORST ensemble. While increasing the size of the WORST ensemble by just 1 or 2 more members would increase the respective validity of $\sigma$ (and have little impact on projections from the BEST ensemble), the authors do not find it reasonable to label any further models as poor performers, due to the close proximity of their overall scores (i.e. there is not enough evidence to take any more models from the BEST ensemble). Therefore, great care is advised when considering projections of $\sigma$ for the WORST ensemble due to is sensitivity for small samples. This ensemble is included as a point of comparison with the ALL and BEST ensembles, rather than as a robust projection.

The statistical significance was calculated between the ALL ensemble and the 2 ensemble subsets for the entire study (PCCSP) region, as well as 3 featurebased regions: the SPCZ, ITCZ and WPM regions. The non-parametric Kolmogorov-Smirnov test (Stephens 1970,1986$)$ was used to determine if the ensemble change of the subset ensemble (BEST, WORST) was significantly different from the ALL ensemble. The null hypothesis that the ensemble subset change for the region is not distinguishable from the ALL ensemble change is rejected at the $5 \%$ significance level. This was performed to determine if the difference between current model performance and future projections varies across the domains affected by the respective climate features. Since the CMIP3 GCMs can only provide projections at course resolution, great care needs to be taken when interpreting both evaluation and projection results at sub- 
regional scales (i.e. those smaller than continental). The size of the PCCSP region and the feature-based regions were chosen with this in mind.

Projections were also calculated for the B1 and A1B SPES scenarios and also for 20 yr periods centred on 2030 and 2055. While not presented, spatial patterns of change and their statistical significance were mostly the same across scenarios and time periods but generally of lower magnitude under the lower emission scenarios as well as time periods that occur earlier in the 21st century (see Section 4.1).

\section{RESULTS}

\subsection{Surface air temperature (TAS)}

Fig. 3 shows the mean TAS 2090 projections for ALL, BEST and WORST ensembles for annual, MJJASO and NDJFMA under the A2 scenario. Projections from the ALL and BEST ensembles show warming of $3^{\circ} \mathrm{C}$ for most of the region. The BEST ensemble projects up to $4^{\circ} \mathrm{C}$ warming over the Pacific cold tongue. This larger increase may be due to a cooler baseline climatology and the GCM 'cold tongue bias', where the model simulated cold tongue extends too far west (e.g. Bellucci et al. 2010). The ALL ensemble projects 0.5 to $1.0^{\circ} \mathrm{C}$ less warming over the eastern equatorial area of the PCCSP region than the BEST ensemble. Increases of $2.5^{\circ} \mathrm{C}$ in the southeast are common across all 3 ensembles. Although projections made by the ALL and BEST ensembles appear very similar in Fig. 3, Table 2 shows that for all regions and seasons the BEST ensemble is statistically significantly warmer. Furthermore the WORST ensemble is statistically significantly cooler than the ALL ensemble. Regionally-averaged differences of change are almost always positive in the BEST ensemble and almost always negative for the
WORST ensemble, when compared with the ALL ensemble. The BEST models cluster towards larger magnitudes of change in the ALL ensemble, and the WORST models towards lower magnitudes.

Fig. 4 shows the standard deviation $(\sigma)$ of the variability in projections between ensemble members of each ensemble (see Fig. 3). Lower (higher) values of $\sigma$ indicate lower (higher) uncertainty. Uncertainty is lower in the BEST ensembles where $\sigma$ for most of the region is no more than $0.4^{\circ} \mathrm{C}$. Much of the north/ northeast and equatorial area of the PCCSP region has $\sigma$ values of 0.4 to $0.6^{\circ} \mathrm{C}$ in the ALL ensembles with some seasonal variation of this magnitude in the south. Higher $\sigma$ values in the ALL ensemble in these locations may be related to known biases in climate features (namely the ITCZ and SPCZ; Moise \& Delage 2011) and the cold tongue (e.g. Bellucci et al. 2010). The BEST ensemble also has higher $\sigma$ values over the cold tongue; however the magnitudes and size of this area are smaller than the corresponding ALL ensemble. The WORST ensemble consistently has the highest uncertainty across almost the entire region, particularly in the eastern part of the PCCSP domain and the north and south of the region, where $\sigma$ is between $0.5^{\circ} \mathrm{C}$ to $0.8^{\circ} \mathrm{C}$. Some uncertainty is reduced in projections of TAS when using only those models with reasonable skill, as the BEST ensemble has a smaller spread than the ALL ensemble.

\subsection{Precipitation (PR)}

Fig. 5 shows projections of percentage change in PR for 2080-2099 relative to 1980-1999. Across all ensembles and full/half-years the largest amount of change occurs over the equator, where increases of at least $60 \%$ are evident. Projections appear similar in the BEST and ALL ensembles, including increases of up to $30 \%$ in the northwest and southeast, which

Table 2. Regionally averaged change in surface air temperatures (TAS; ${ }^{\circ} \mathrm{C}$ ) calculated for the BEST and WORST ensembles for annual, November to April (NDJFMA) and May to October (MJJASO) projections. Values in parentheses represent the bias from the ALL ensemble average, where significant $(\mathrm{p}<0.05)$ differences are shown in bold. PCCSP: Pacific Climate Change Science Program region spans $25^{\circ} \mathrm{S}$ to $20^{\circ} \mathrm{N}, 120^{\circ} \mathrm{E}$ to $170^{\circ} \mathrm{W}$ (excluding Australia); WPM: West Pacific Monsoon $10^{\circ} \mathrm{S}$ to $20^{\circ} \mathrm{N}, 120^{\circ} \mathrm{E}$ to $155^{\circ} \mathrm{E}$; ITCZ: Intertropical Convergence Zone $0^{\circ}$ to $20^{\circ} \mathrm{N}, 155^{\circ} \mathrm{E}$ to $170^{\circ} \mathrm{W}$; SPCZ: South Pacific Convergence Zone $25^{\circ} \mathrm{S}$ to $0^{\circ}, 155^{\circ} \mathrm{E}$ to $170^{\circ} \mathrm{W}$

\begin{tabular}{|c|c|c|c|c|c|c|}
\hline \multirow[t]{2}{*}{ Region } & \multicolumn{3}{|c|}{$-\mathrm{BEST}-$} & \multicolumn{3}{|c|}{ - WORST - } \\
\hline & Annual & NDJFMA & MJJASO & Annual & NDJFMA & MAJJASO \\
\hline PCCSP & $2.76(\mathbf{0 . 0 9 )}$ & 2.76 (0.09) & $2.75(\mathbf{0 . 0 8 )}$ & $2.33(-\mathbf{0 . 3 4})$ & $2.31(\mathbf{- 0 . 3 6 )}$ & $2.34(-\mathbf{0 . 3 2})$ \\
\hline WPM & $2.78(\mathbf{0 . 0 9 )}$ & $2.76(\mathbf{0 . 0 9 )}$ & 2.79 (0.09) & $2.36(-\mathbf{0 . 3 4})$ & $2.34(-\mathbf{0 . 3 3})$ & $2.37(-\mathbf{0 . 3 3})$ \\
\hline ITCZ & 2.92 (0.13) & 2.89 (0.12) & 2.93 (0.13) & $2.31(\mathbf{- 0 . 4 8 )}$ & $2.30(-\mathbf{0 . 4 7})$ & $2.31(\mathbf{- 0 . 4 8 )}$ \\
\hline SPCZ & $2.68(\mathbf{0 . 0 7})$ & $2.71(\mathbf{0 . 0 8 )}$ & 2.64 (0.06) & $2.33(-\mathbf{0 . 2 7})$ & $2.31(-\mathbf{0 . 3 2})$ & $2.34(-\mathbf{0} .22)$ \\
\hline
\end{tabular}



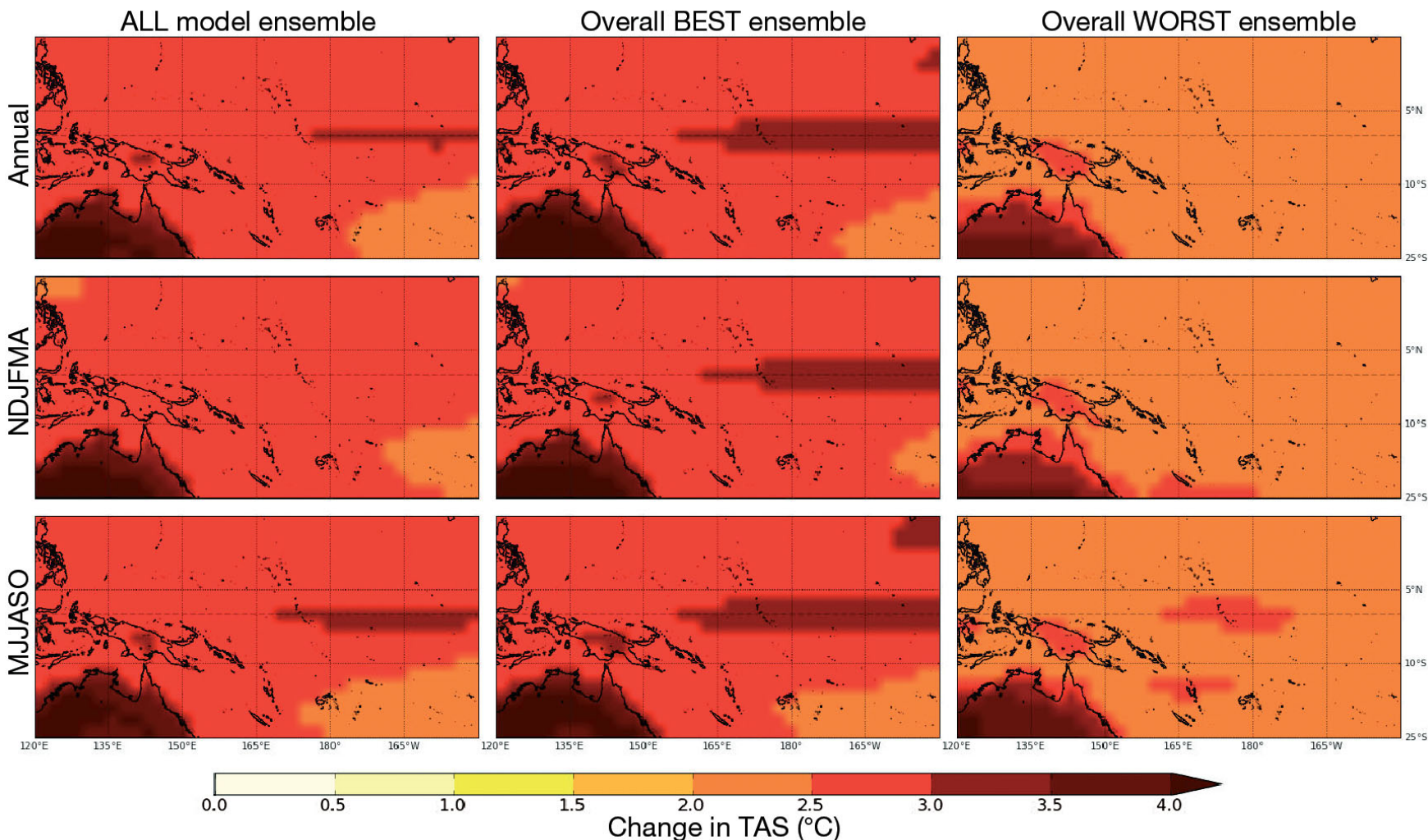

Fig. 3. Ensemble mean surface air temperature (TAS) change for the Pacific Climate Change Science Program (PCCSP) region under the A2 emissions scenario for a $20 \mathrm{yr}$ period centred on 2090 using the 3 model ensembles (ALL, BEST, WORST) projected annually and 6-monthly (NDJFMA: November to April; MJJASO: May to October)
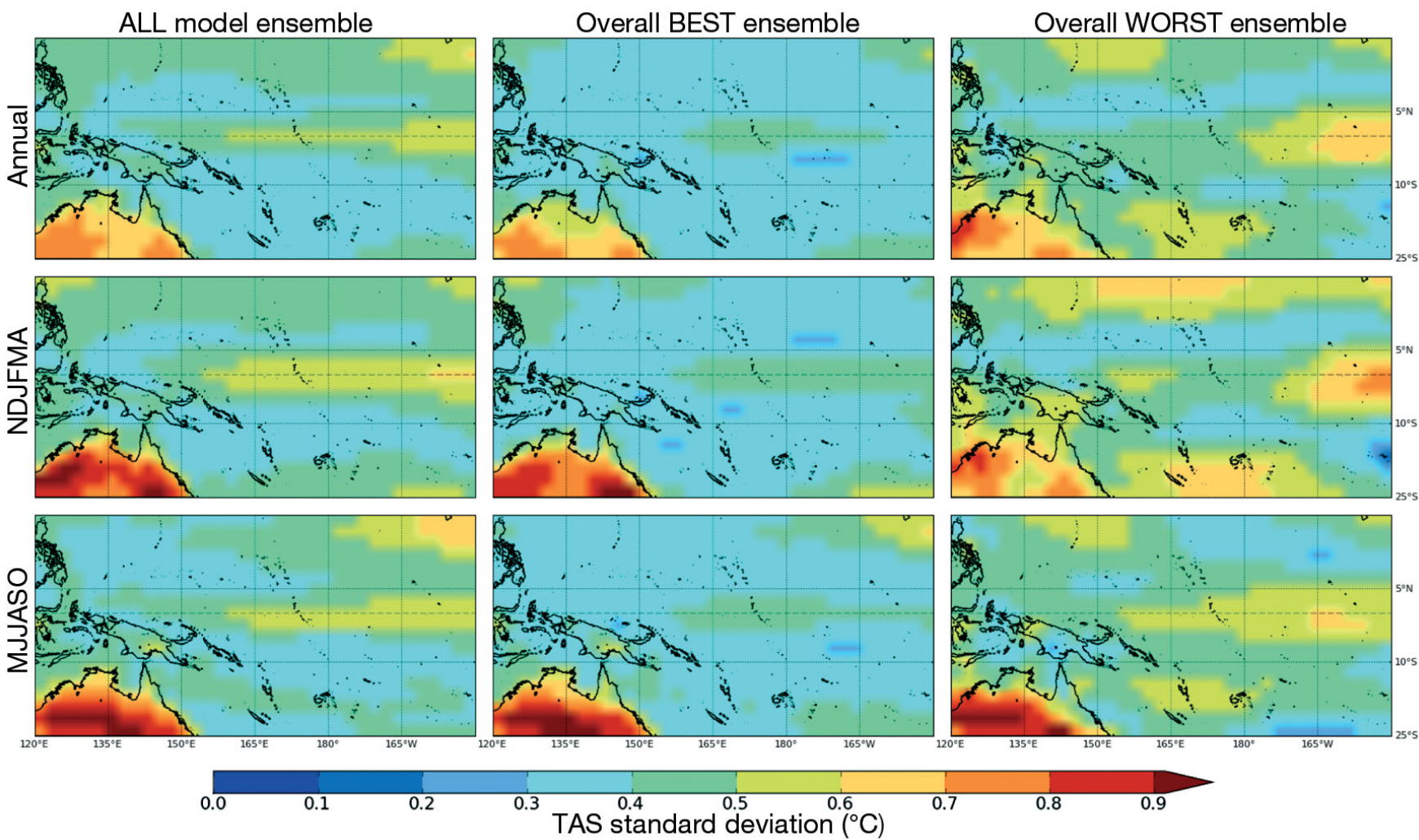

1.7

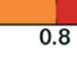

Fig. 4. Ensemble mean uncertainty (the ensemble variability, measured by the standard deviation) of surface air temperature (TAS) change for the PCCSP region under the A2 scenario for a 20 yr period centred on 2090 using the 3 model ensembles (ALL, BEST, WORST) projected annually and 6-monthly (NDJFMA: November to April; MJJASO: May to October) 
encompasses the domain of the SPCZ, during the annual and NDJFMA projections (Vincent 1994, Brown et al. 2011), increases of 30 to $40 \%$ in the north, which encompasses the range of the ITCZ, during all seasons (Waliser \& Gautier 1993); and decreases near East Timor during MJJASO. Increases in PR are also evident in the WORST ensembles but are slightly smaller in size over the equator in the annual and MJJASO projections and are larger in the south of the region during all periods. Increases in precipitation in the north of the region are also less pronounced in the WORST ensemble. Projections using the BEST ensemble are generally not significantly different from the ALL ensemble (with the exception of annual projections over the PCCSP and ITCZ regions, and MJJASO projections over the PCCSP and SPCZ regions). On the other hand, projections from the WORST ensemble generally are significantly different from those of the ALL ensemble (Table 3). Similar to TAS, regionally averaged PR biases are almost always positive in the BEST ensembles and almost always negative for the WORST ensembles when compared with the ALL ensemble. That is, there is a greater increase in precipitation in the BEST models than the WORST models.

Fig. 6 shows the ensemble standard deviation among each ensemble presented in Fig. 5. Areas of higher ensemble variability (up to $100 \%$ ) correspond to areas of largest increase in Fig. 5 (most notably over the cold tongue) particularly during MJJASO using the BEST and ALL ensembles. Values of $\sigma$ of up to $50 \%$ are associated with the drying over East Timor during MJJASO, and $\sigma$ values of $40 \%$ occur zonally at $10^{\circ} \mathrm{N}$ during NDJFMA, which may be related to ensemble members differing in their ITCZ positioning (not shown). Higher $\sigma$ values associated with the cold tongue show a more zonal pattern in the WORST ensembles and extend further west. Values of $\sigma$ in the WORST ensembles are around $10 \%$ less in some areas than those of the other 2 ensembles, which are comparable to one another. The smaller ensemble variability in the WORST ensemble is likely to be due to the smaller sample size.

\subsection{Wind speed (WSP)}

Fig. 7 presents changes in WSP for the PCCSP region. When considering ALL and BEST ensemble projections, the annual mean WSP decreases by 5 to $10 \%$ in the north and increases by 5 to $15 \%$ south of $5^{\circ} \mathrm{S}$ and in the far northwest. This implies a weakening of the Walker cell along the equator (changes are between -5 and $-10 \%$ between $5^{\circ} \mathrm{N}$ and $5^{\circ} \mathrm{S}$ ), which is consistent with other studies (e.g. Vecchi et al. 2006, Power \& Kociuba 2010). Changes in the southwest are $5 \%$ smaller in the BEST ensemble than they are in the ALL ensemble. Similar north/south spatial patterns occur during MJJASO; however increases in the south are pushed towards $10^{\circ} \mathrm{S}$ and vary between 15 and $45 \%$. Decreases in the centre of the region are $5 \%$ larger in the BEST ensemble than in the ALL ensemble, and decreases also appear in the west of the region. Projections for NDJFMA using the BEST ensemble show increases of 5 to $10 \%$ in the far north and south, increases of 10 to $30 \%$ stretching southwest from Papua New Guinea, and increases of $30 \%$ in the west near East Timor. The rest of the region shows decreases of around $5 \%$, and most other projections in the BEST ensemble are generally similar to those in the ALL ensemble, with the exception of an increase in the centre of the region. Considerable differences are evident in the WORST ensembles. Much of the region (particularly the north) has increases of up to $30 \%$ for the annual mean and increases exceeding $45 \%$ that occur east and west of Papua New Guinea, related to seasonal shifts of the WPM. Decreases of 10 to $25 \%$ occur southeast of Papua New Guinea during NDJFMA, which encompasses at least part of the SPCZ. Increases of at least $45 \%$ occur in the northwest during MJJASO, again possibly related to seasonal shifts in the WPM. In con-

Table 3. Regionally averaged change in precipitation ( $\left.\mathrm{PR}_{i} \%\right)$ from the base period (1980-1999) calculated for the BEST and WORST ensembles for annual, November to April (NDJFMA) and May to October (MJJASO) projections. Values in parentheses represent the bias from the ALL ensemble average, where significant $(p<0.05)$ differences are shown in bold. See Table 2 legend for region abbreviations and locations

\begin{tabular}{|c|c|c|c|c|c|c|}
\hline \multirow[t]{2}{*}{ Region } & \multicolumn{3}{|c|}{ - BEST - } & \multicolumn{3}{|c|}{ - WORST } \\
\hline & Annual & NDJFMA & MJJASO & Annual & NDJFMA & MAJJASO \\
\hline PCCSP & $15.97(\mathbf{0 . 8 2})$ & $16.33(1.20)$ & 18.85 (0.37) & $12.06(\mathbf{- 3 . 0 9 )}$ & $10.62(-\mathbf{4 . 5 1})$ & $17.08(\mathbf{- 1 . 4 0 )}$ \\
\hline WPM & $7.74(0.22)$ & $9.53(0.89)$ & $6.72(-0.34)$ & $6.69(-0.83)$ & $5.28(-3.35)$ & 8.34 (1.28) \\
\hline ITCZ & 26.28 (2.61) & $21.94(2.57)$ & $37.58(2.20)$ & $13.88(\mathbf{- 9 . 7 9 )}$ & $9.75(\mathbf{- 9 . 6 2 )}$ & $27.13(\mathbf{- 8 . 2 5 )}$ \\
\hline SPCZ & $17.45(0.35)$ & $19.62(0.61)$ & 18.66 (0.32) & $15.81(\mathbf{- 1 . 3 0})$ & $16.71(-2.30)$ & 17.15 (-1.19) \\
\hline
\end{tabular}



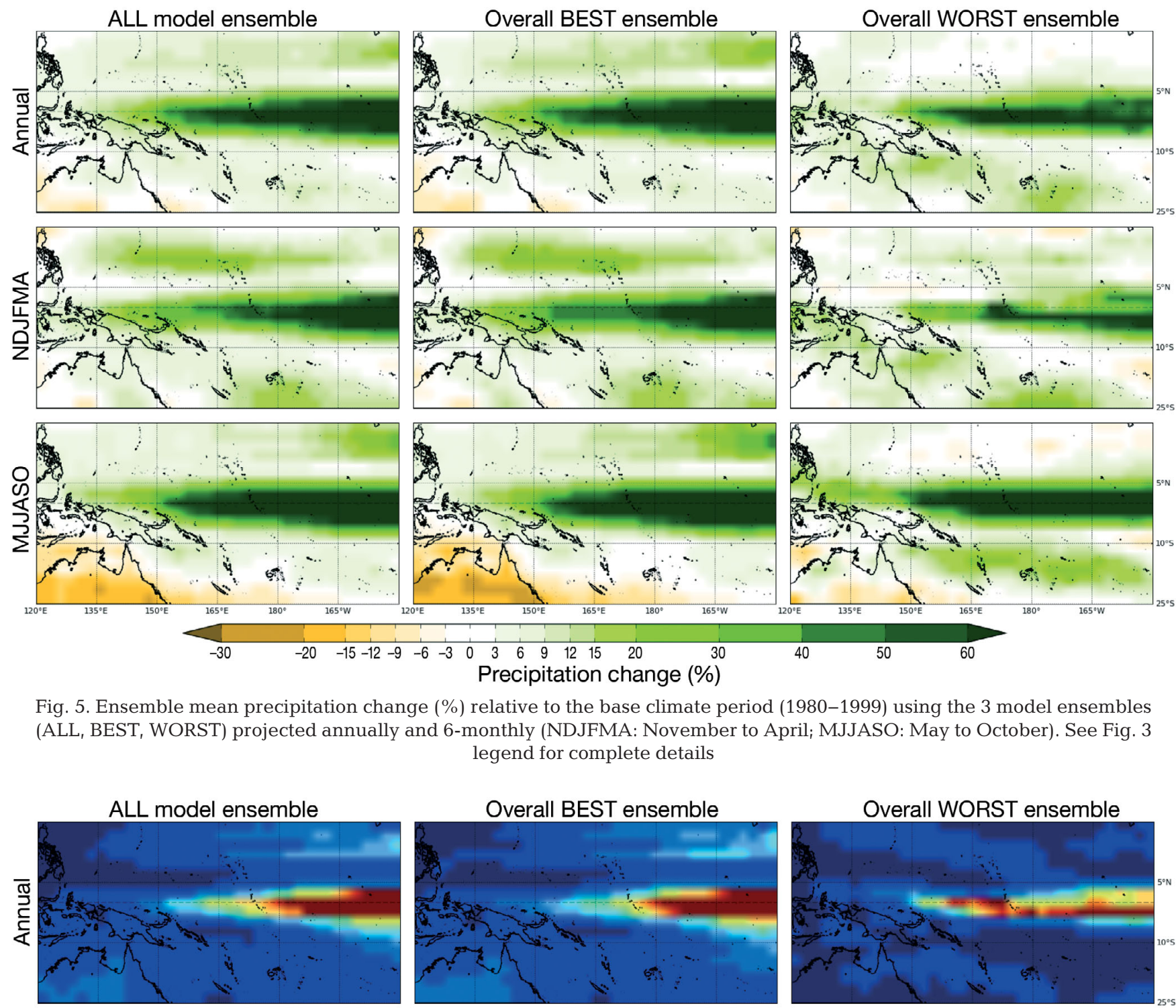

Fig. 5. Ensemble mean precipitation change (\%) relative to the base climate period (1980-1999) using the 3 model ensembles (ALL, BEST, WORST) projected annually and 6-monthly (NDJFMA: November to Aprili MJJASO: May to October). See Fig. 3 legend for complete details
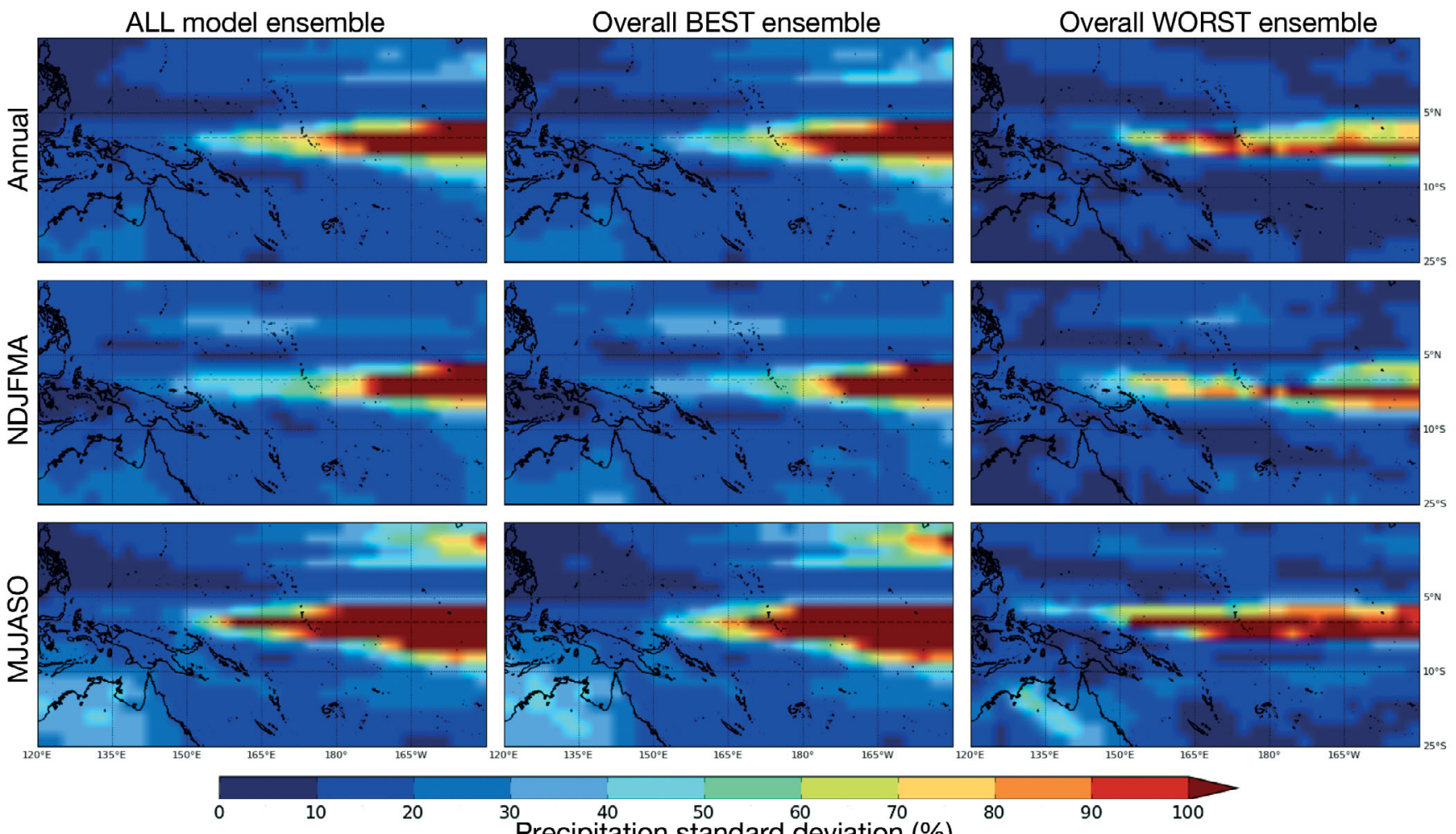

${ }^{30} \stackrel{40}{40} \stackrel{50}{5} \stackrel{60}{60} \quad \frac{70}{70}(\%)$

Fig. 6. Ensemble mean uncertainty in precipitation change (\%) relative to the base climate period (1980-1999) using the 3 model ensembles (ALL, BEST, WORST) projected annually and 6-monthly (NDJFMA: November to April; MJJASO: May to October). 
junction with results from NDJFMA, the poorer performing models tend to exacerbate increases of WSP over the WPM spatial domain. Wind speeds tend to increase over much of the region in the WORST ensemble during NDJFMA, with the exception of in and immediately west of Papua New Guinea.

Table 4 presents the feature-based regional projections and differences for WSP and shows that almost all biases in the ensemble subsets are distinguishable from the ALL ensemble when averaged for each region. Biases in the BEST and WORST ensembles are negative and positive, respectively, implying projections are smaller and greater, respectively, in magnitude than those of the ALL ensemble. Fig. 8 shows the ensemble $\sigma$ for the corresponding categories presented in Fig. 7. Among the WORST ensemble, highest uncertainty occurs in areas with the largest projected increases (e.g. the northwest during MJJASO). This is also the case for the ALL and BEST ensembles, although larger $\sigma$ values also occur in the centre of the region during MJJASO using the BEST ensemble (an area which shows slightly larger decreases) and northeast of Papua New Guinea for the annual projections in the BEST and ALL ensembles. In the ALL and BEST ensembles uncertainty generally decreases in the northeast by $5 \%$ for the annual mean, to the east of Papua New Guinea during NDJFMA by up to $25 \%$, and by 5 to $10 \%$ in the west and northeast during MJJASO.

\subsection{Wind direction (WDIR)}

For wind direction, a high degree of similarity is evident between the ALL and BEST ensembles (Fig. 9). Changes just south of the equator are in a clockwise direction, so the direction of flow becomes more easterly in this region. This change is of higher magnitude (up to $15^{\circ}$ ) during NDJFMA and contracts north during MJJASO. This easterly shift covers a similar area to regions of largest PR increase in Fig. 5. Easterly flows also become more prominent in the southwest during the annual and MJJASO periods and in the south during NDJFMA and MJJASO. Seasonal differences occur in the north particularly in the ALL ensemble, where change is generally clockwise (anticlockwise) during NDJFMA (MJJASO), which result in more zonal easterly winds. WDIR in the northeast becomes more meridional during MJJASO in the ALL ensemble but becomes more zonal in the BEST ensemble. Changes in the west appear variable for both of these ensembles particularly for the annual mean, which can be explained by the lack of dominating flow associated with the seasonal shift of the WPM and the higher uncertainty among the ensemble members to capture the change in direction. Similar to Fig. 7, considerable disparity is evident in the WORST ensemble when compared to the ALL and BEST ensembles. This is particularly true west of Papua New Guinea during NDJFMA, which also corresponds to an area of large WSP increase (Fig. 7).

Large clockwise (indicative of a more easterly flow) changes are also evident in the central north and southeast during MJJASO and to a lesser extent in annual projections. Large anticlockwise changes (at least $10^{\circ}$ ) are evident southwest of Papua New Guinea and in the northeast for the annual mean, in the northeast and northwest during MJJASO, and in the south during NDJFMA. Overall changes of flow, however, are generally still in the easterly direction. Regionally averaged projections of the ensemble subsets (Table 5) are generally significantly different from the ALL ensemble, except over the WPM. Hence, removing the WORST models generally makes a significant difference to the projections of wind direction change.

Similar to Section 3.3, larger WDIR values of $\sigma$ (Fig. 10) are generally associated with larger magnitudes of change (in both directions) that are presented in Fig. 9. Across all ensembles and full/halfyears for areas where projections are $\pm 2^{\circ}, \sigma$ values are generally no more than $5^{\circ}$. The exception to this

Table 4. Regionally averaged percentage change in wind speed (WSP; \%) from the base period (1980-1999) calculated for the BEST and WORST ensembles for annual, November to April (NDJFMA) and May to October (MJJASO) projections. Values in parentheses represent the bias from the ALL ensemble average, where significant $(p<0.05)$ differences are shown in bold. See Table 2 legend for region abbreviations and locations

\begin{tabular}{|c|c|c|c|c|c|c|}
\hline \multirow[t]{2}{*}{ Region } & \multicolumn{3}{|c|}{ - BEST - } & \multicolumn{3}{|c|}{ WORST } \\
\hline & Annual & NDJFMA & MJJASO & Annual & NDJFMA & MAJJASO \\
\hline PCCSP & $0.99(\mathbf{- 1 . 0 4 )}$ & $-1.50(-\mathbf{1 . 1 5})$ & $5.07(\mathbf{- 1 . 5 9 )}$ & $8.77(6.74)$ & $10.16(\mathbf{7 . 5 0 )}$ & $16.96(\mathbf{1 0 . 3 0})$ \\
\hline WPM & $0.07(-\mathbf{0 . 3 8})$ & $0.93(-1.04)$ & $-4.53(-\mathbf{4 . 0 4 )}$ & 2.94 (2.49) & $8.73(\mathbf{6 . 7 6})$ & $25.77(\mathbf{2 6 . 2 6})$ \\
\hline ITCZ & $-6.03(-2.23)$ & $-0.71(-\mathbf{0 . 9 6})$ & $-8.58(-2.63)$ & $10.68(\mathbf{1 4 . 4 9 )}$ & $6.52(6.27)$ & $11.15(\mathbf{1 7 . 1 0})$ \\
\hline SPCZ & $5.31(-\mathbf{0 . 7 9})$ & $2.86(\mathbf{- 1 . 8 9 )}$ & $16.51(0.36)$ & 11.25 (5.15) & $17.04(\mathbf{1 2 . 2 8 )}$ & $13.84(-2.31)$ \\
\hline
\end{tabular}



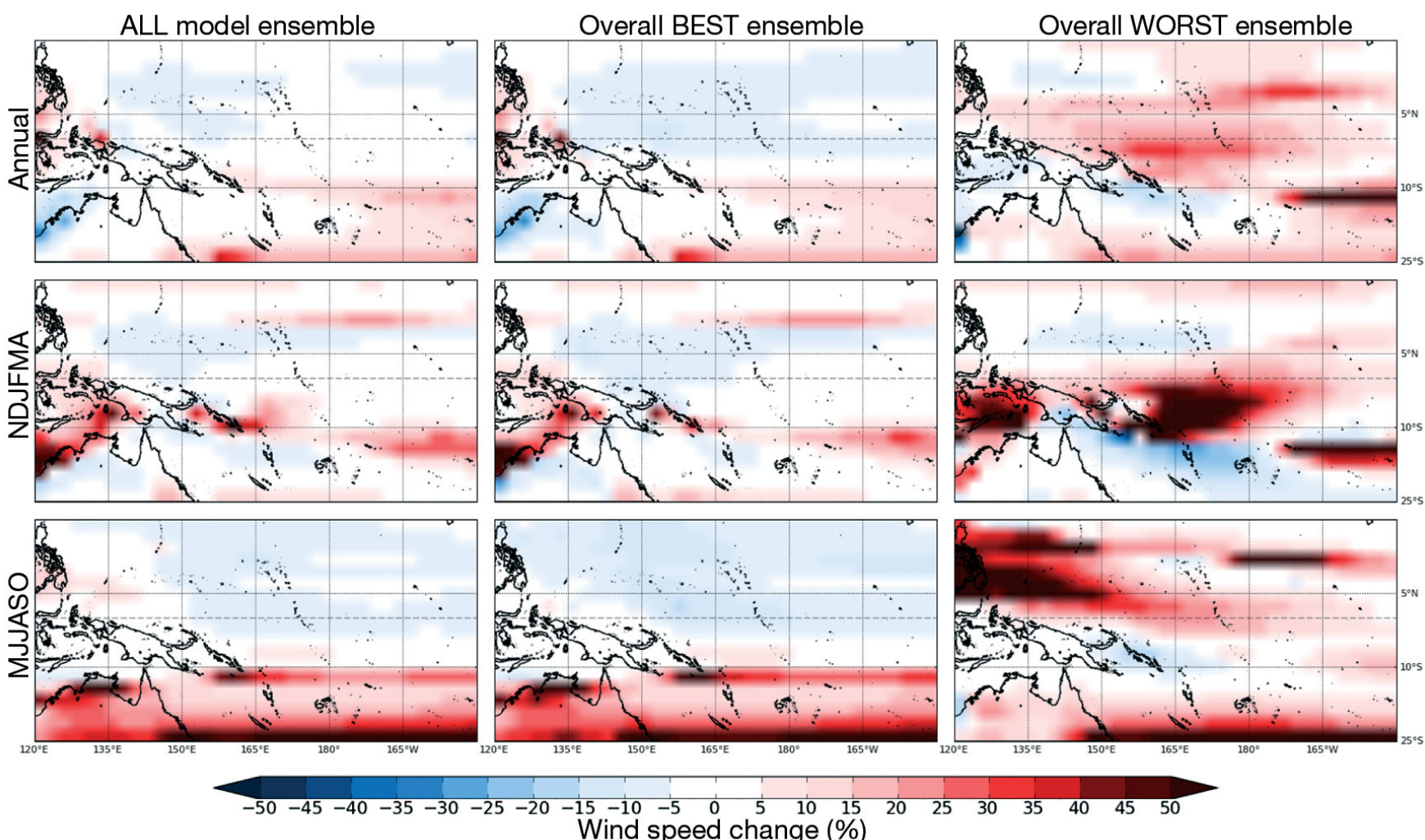

Fig. 7. Ensemble mean change in wind speed (\%) relative to the base climate period (1980-1999) using the 3 model ensembles (ALL, BEST, WORST) projected annually and 6-monthly (NDJFMA: November to April; MJJASO: May to October). See Fig. 3 legend for complete details
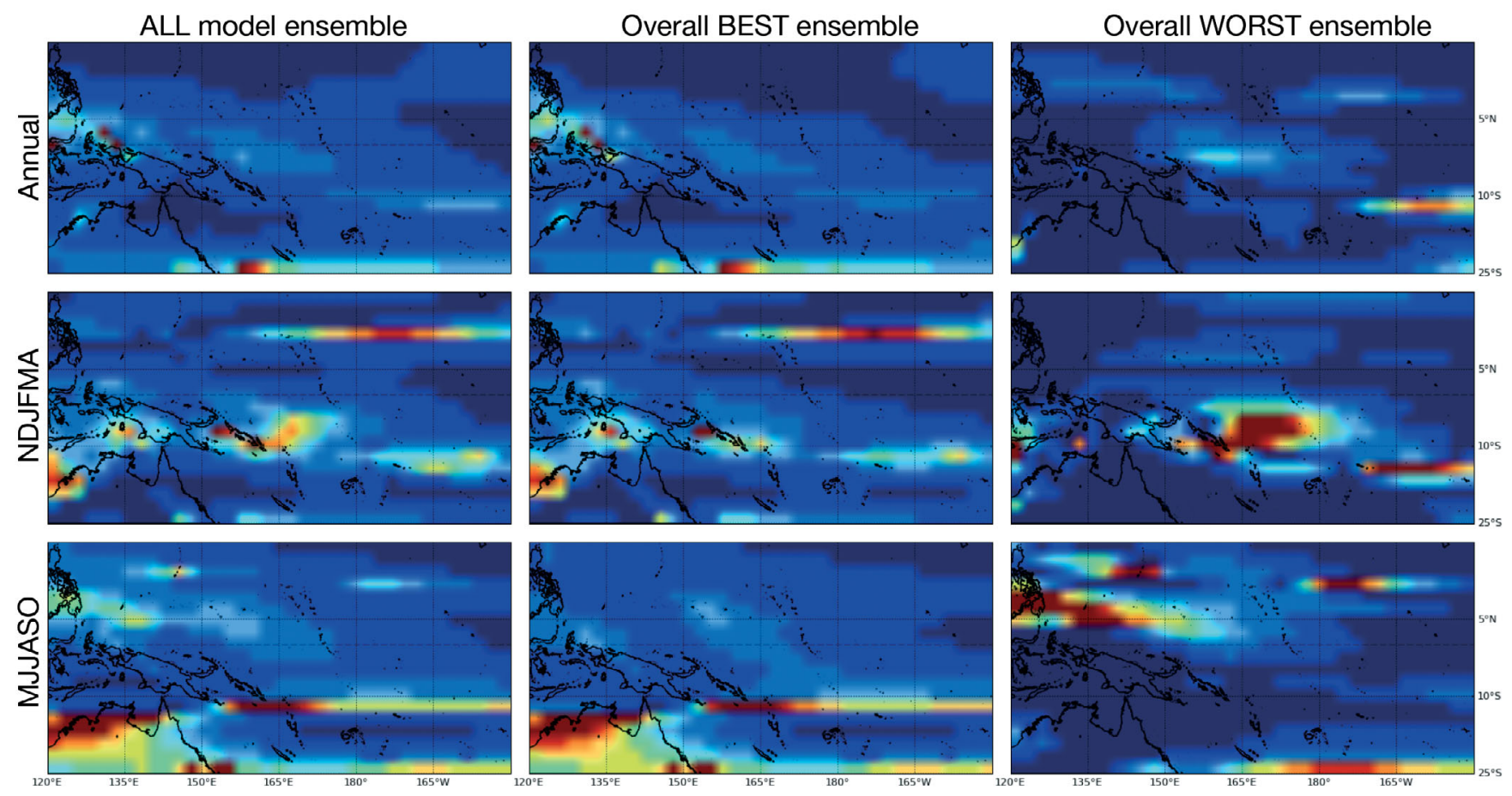

${ }^{30}$ Wind $\stackrel{40}{\text { speed standard }} \stackrel{50}{\text { deviation }} \stackrel{70}{\%} \%$

Fig. 8. Ensemble mean uncertainty in wind speed change (\%) relative to the base climate period (1980-1999) using the 3 model ensembles (ALL, BEST, WORST) projected annually and 6-monthly (NDJFMA: November to April; MJJASO: May to October). 
is over the WPM region during MJJASO for the BEST and ALL ensembles, where $\sigma$ is between 10 and $20^{\circ}$. Values of $\sigma$ of around $30^{\circ}$ occur in these ensembles over Papua New Guinea and East Timor during NDJFMA, which coincides with the positioning of the WPM during austral summer and areas of up to $10^{\circ}$ anticlockwise change in Fig. 9. In the BEST and ALL ensembles, $\sigma$ values northwest of Papua New Guinea are at least $30^{\circ}$ for the annual mean. Uncertainty in WDIR change tends to be slightly higher over the SPCZ region ( $\sigma$ of 10 to $15^{\circ}$ ) particularly during NDJFMA. Uncertainty in projected changes in the direction of flow is high at $10^{\circ} \mathrm{N}$ and $10^{\circ} \mathrm{S}$ during NDJFMA and MJJASO, respectively. In the WORST ensemble, $\sigma$ values of at least 10 to $20^{\circ}$ occur in the central northeast and northwest and southeast during the annual and NDJFMA, east of Papua New Guinea during NDJFMA, and in the northeast and northwest during MJJASO. All of these are areas of larger changes in Fig. 9.

\section{DISCUSSION}

\subsection{Ensemble projections and uncertainty}

Projections presented for the study region under the SRES A2 scenario by 2090 show warming temperatures of around $3^{\circ} \mathrm{C}$, PR increases of at least $60 \%$ over the equator and 10 to $30 \%$ in the north and south, PR decreases of up to $20 \%$ in the far south and over East Timor during MJJASO, WSP decreases (increases) in the north (south), and winds tending towards a more easterly direction. Such projections are consistent across the ALL and BEST ensembles; however the WORST ensemble tends to be substantially different. Despite similar magnitudes and spatial patterns in Figs. 3, 5, 7 \& 9 for the BEST and ALL ensembles, regionally averaged mean ensemble projections by the BEST ensembles are always signifi- cantly different from the ALL ensemble for TAS (Table 2), almost always statistically significantly different for WSP (Table 4), and statistically significantly different for some regions and seasons for PR and WDIR (Tables $3 \& 5$ ). Furthermore, projections from the WORST ensembles are always statistically significantly different from the ALL ensemble for each variable, time period, and region, illustrating that models which have lower skill in simulating current conditions produce distinguishably different projections from the other models in the ALL ensemble. Similar results have also been found over other regions using the CMIP3 GCMs (e.g. Perkins et al. 2009).

Uncertainty (in terms of the inter-model spread) is reduced when omitting the less skilled models for TAS projections (Fig. 3) and in some regions for WSP (Fig. 7). However uncertainty is generally comparable across the ALL and BEST ensembles for PR (Fig. 5) and WDIR (Fig. 9). Therefore in the latter 2 cases we cannot say that some of the uncertainty in projections of change for the respective variables is reduced when less skilled models are eliminated, at least over the PCCSP region. While we have good reason to place higher confidence in the BEST ensemble compared to the ALL ensemble and (especially) the WORST ensemble, the spread of the individual members is not correlated to model ability for PR and WDIR, i.e. members within the BEST ensemble do not cluster around projected changes in the respective variables any differently than members in the corresponding ALL ensemble (Figs. 6 \& 10).

By 2030 and 2055 under the B1 and A1B scenarios, projected changes in all variables are similar to those presented in this paper but are of smaller magnitude. Changes in TAS by 2030 are up to $1^{\circ} \mathrm{C}$ for the region across all scenarios, seasons and ensembles. By 2055, spatial patterns emerge where the northeast warms $0.5^{\circ} \mathrm{C}$ more than the rest of the PCCSP region. Similar warming patterns in TAS (Fig. 3) are present

Table 5. Regionally averaged change in wind direction (WDIR; ${ }^{\circ}$ ) from the base period (1980-1999) calculated for the BEST and WORST ensembles for annual, November to April (NDJFMA) and May to October (MJJASO) projections. Positive changes imply a clockwise change relative to the base period flow, negative changes an anticlockwise change. Values in parentheses represent the bias from the ALL ensemble average, where significant $(p<0.05)$ differences are shown in bold. See Table 2 legend for region abbreviations and locations

\begin{tabular}{|c|c|c|c|c|c|c|}
\hline \multirow[t]{2}{*}{ Region } & \multicolumn{3}{|c|}{ - BEST - } & \multicolumn{3}{|c|}{ - WORST } \\
\hline & Annual & NDJFMA & MJJASO & Annual & NDJFMA & MAJJASO \\
\hline PCCSP & $0.61(0.16)$ & $0.43(-\mathbf{0 . 2 4})$ & -0.39 (0.40) & $-0.58(\mathbf{- 1 . 0 3})$ & 2.20 (1.54) & $-3.40(-\mathbf{2 . 6 0})$ \\
\hline WPM & $-1.06(-0.19)$ & $-1.21(-0.35)$ & $0.55(0.21)$ & $0.40(1.26)$ & $1.40(\mathbf{2 . 2 5})$ & $-1.01(\mathbf{- 1 . 3 6 )}$ \\
\hline ITCZ & $-0.73(-0.09)$ & $-0.72(-\mathbf{0 . 2 5})$ & -0.64 (0.77) & $-0.08(\mathbf{0 . 5 6 )}$ & 2.63 (1.65) & $-6.40(\mathbf{- 4 . 9 9 )}$ \\
\hline SPCZ & $2.83(\mathbf{0 . 5 0 )}$ & $1.73(-\mathbf{0 . 2 9 )}$ & $-0.13(0.30)$ & $-0.90(-3.23)$ & 3.90 (1.88) & $-2.36(\mathbf{- 1 . 9 3 )}$ \\
\hline
\end{tabular}



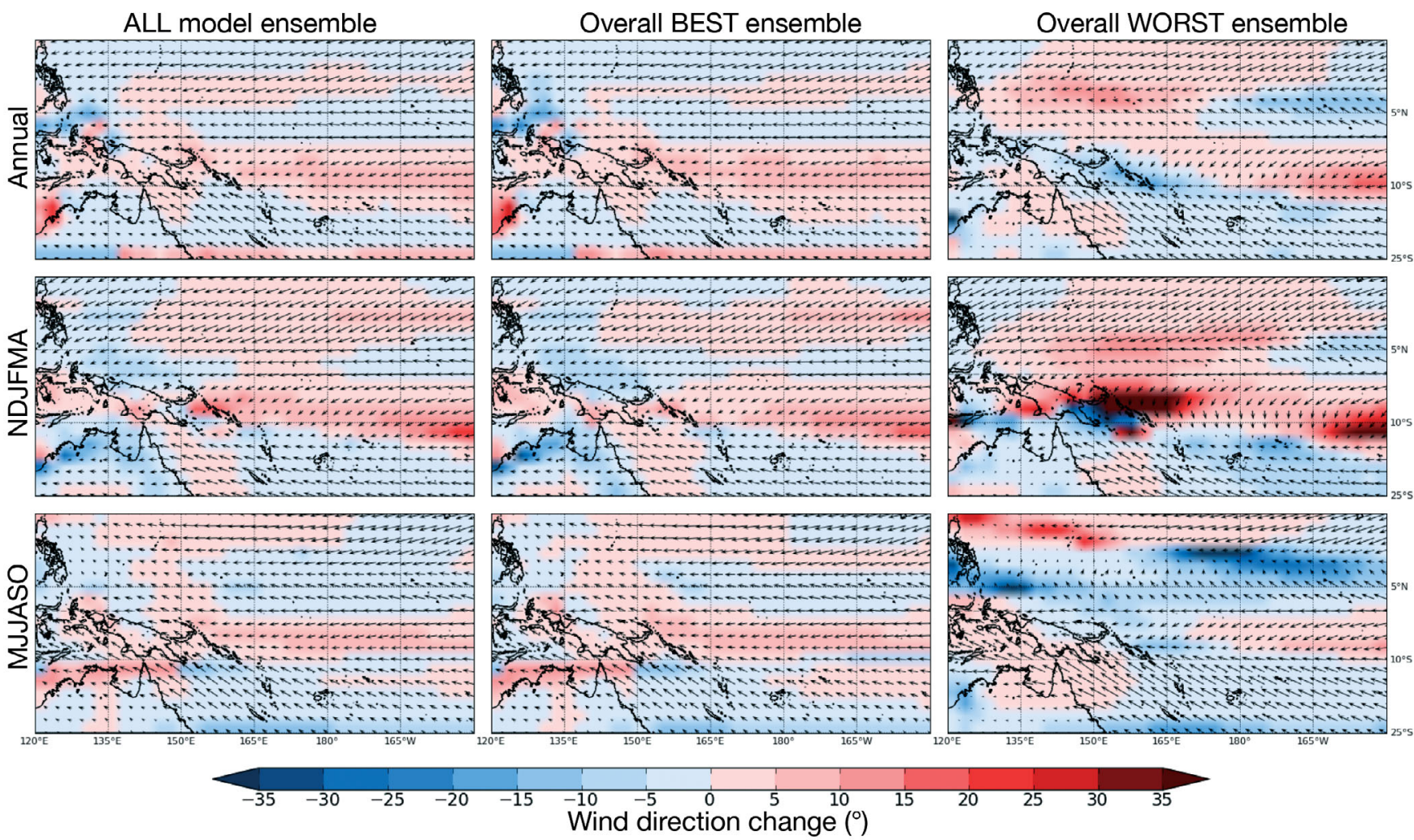

Fig. 9. Ensemble mean change in wind direction $\left({ }^{\circ}\right)$ using the 3 model ensembles (ALL, BEST, WORST) projected annually and 6-monthly (NDJFMA: November to April; MJJASO: May to October). Vectors indicate ensemble mean direction of flow during the base period. See Fig. 3 legend for complete details
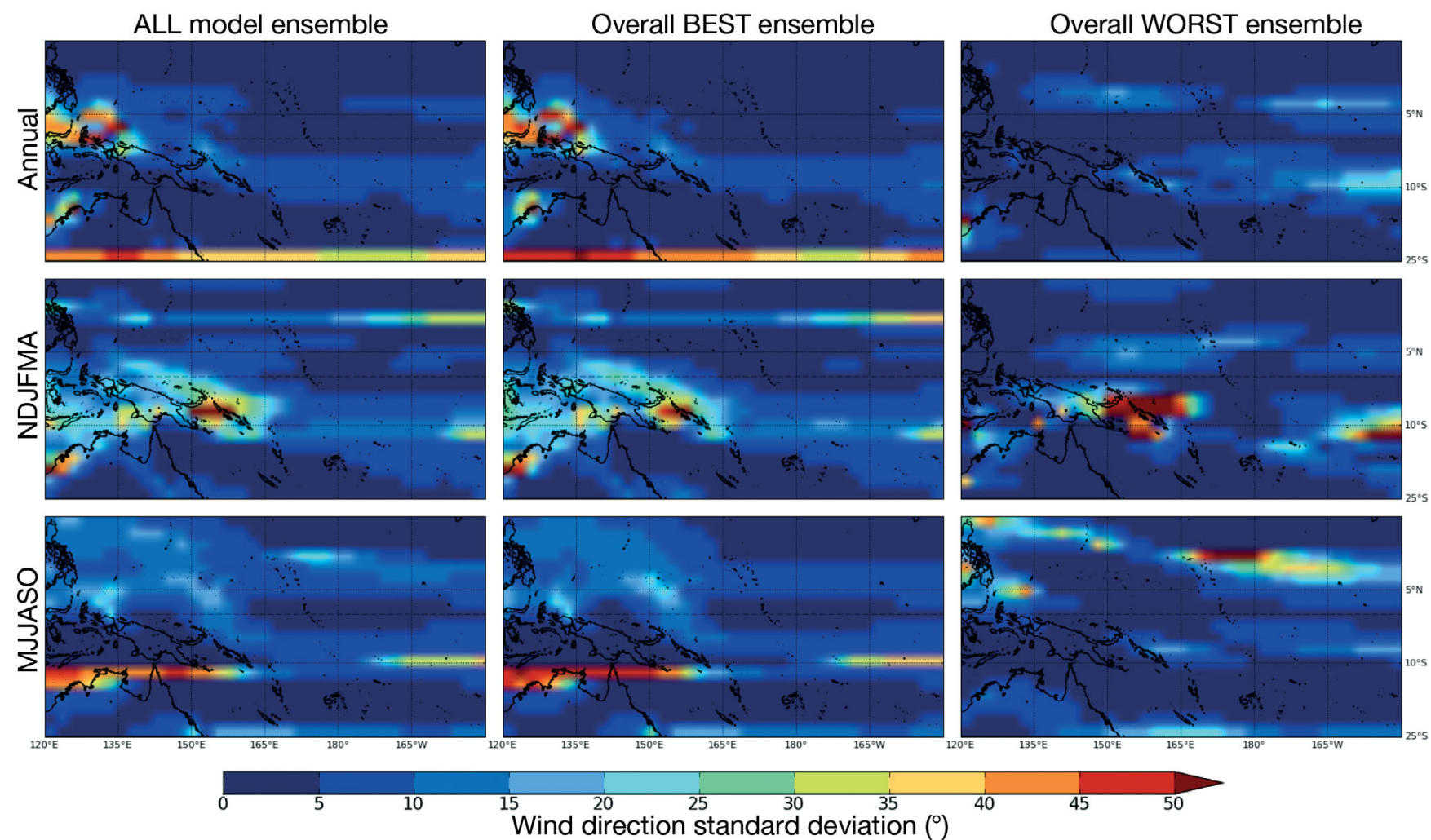

Wind direction standard deviation $\left({ }^{\circ}\right)$

Fig. 10. Ensemble mean uncertainty in wind direction $\left(^{\circ}\right)$ using the 3 model ensembles (ALL, BEST, WORST) projected annually and 6-monthly (NDJFMA: November to April; MJJASO: May to October). Since the standard deviation is a measure of spread, this figure represents the spread of wind direction across the ensemble, rather than the distance from North $\left(0^{\circ}\right)$. See Fig. 4 legend 
under the B1 and A1B scenarios by 2090, though the changes are again smaller in magnitude. TAS values of $\sigma$ are broadly similar across all scenarios and ensembles in 2030. TAS values of $\sigma$ are comparable across the ALL and BEST ensembles under A1B in 2055 and 2090, and across all 3 ensembles under B1. Patterns of PR change in 2030 and 2055 under the A1B and B1 scenarios are similar to those in Fig. 5 but are smaller in magnitude. PR values of $\sigma$ for 2030 and 2055 under the A1B and B1 scenarios are similar to those in Fig. 6, though regions with larger $\sigma$ are of smaller spatial extent. Projections of change in WSP and WDIR and corresponding values of $\sigma$ across B1 and A1B and in 2030 and 2055 are very similar to those presented in Figs. 7 to 10 but are generally smaller in magnitude.

Discrepancies in WSP and WDIR projections and $\sigma$ values (Figs. 7 to 10) have also been presented. The BEST and ALL ensembles show some regions of larger magnitudes, most notably around $10^{\circ} \mathrm{N}$ during NDJFMA (in the east), $10^{\circ} \mathrm{S}$ during MJJASO (in the east and west), and $25^{\circ} \mathrm{S}$ during the annual and MJJASO timescales. The anomalous patterns at $10^{\circ} \mathrm{N}$ are generally due to larger changes in just one member, influencing both the mean change and the standard deviation of the ensembles at these locations. The southern (northern) Hadley and Ferrel cell boundaries of the MPI ECHAM GCM during MJJASO (NDJFMA) occurs at $10^{\circ} \mathrm{S}\left(10^{\circ} \mathrm{N}\right)$, explaining the anomalous projections along these latitudes during the respective seasons (see Fig. 11 for MJJASO WDIR change). The large boundary changes (in terms of direction of flow and speed) of the southern Hadley and Ferrel cells in individual ensemble members can occur as far north as $25^{\circ} \mathrm{S}$ during MJJASO, causing the anomalous WSP and WDIR bands at this latitude in Figs. 7 to 10 during MJJASO and also in the annual projections. Wind speed and direction changes therefore apply at the large scale or regional scale only. This result is also evidence that using only those models with higher skill in simulating changes in the 20th century does not always mean that anomalous errors are removed or that uncertainty is reduced. Metrics that evaluate changes in the Hadley and Ferrel cells should be calculated in future evaluation studies over the Pacific domain, as well as any other region located, even partially, over the subtropics.

\subsection{Changes in drivers and features}

Following the approach of the ADB (2009), we attempt to explain changes in the climate of the
Pacific region in relation to changes in ENSO and major climate features (SPCZ, ITCZ, WPM). These features, as well as ENSO, are important, as they govern the Pacific climate on annual, interannual and longer timescales. Undertaking this task may deepen the understanding of the changes in the west Pacific climate presented above and help us assess the degree of confidence we might have in the projections in particular regions. Changes in ENSO, SPCZ, ITCZ, and WPM within the CMIP3 GCMs are discussed briefly below.

\subsubsection{ENSO}

Since a close coupling exists between TAS and SSTs over the Pacific, changes in TAS from the CMIP3 GCMs under the A2 scenario by 2090 (Fig. 3) reveal that the maximum increase in SST over the domain occurs towards the eastern equatorial area of the PCCSP region (Meehl et al. 2007b). The maximum SST change extends further east in the BEST models and tends to be more restricted to the central Pacific in the WORST models. The changes in the ALL ensemble and in the BEST ensemble somewhat resemble the pattern of SSTs during a typical El Niño event, in the sense that this is also the location of maximum SST anomalies during El Niño events. Interestingly, the location of these anomalies in the WORST ensemble is close to where the Modoki El Niño has its maximum SST anomaly (Ashok et al. 2007). The equatorial easterlies also weaken under global warming (Fig. 9), as they do during El Niño events.

Despite some similarities between the projected climate change signal and the observed El Niño temperature mean state, the use of the term 'El Niño-like' to characterize the fingerprint of global warming in the Pacific is misleading (e.g. Vecchi \& Wittenberg 2010, Collins et al. 2010). This is because the mean pattern of warming by 2090 does not imply that the climate will tend towards conditions experienced during the El Niño phase of ENSO, which is a measure of climate variability rather than a description of the mean state. Furthermore, the extent of agreement between projected El Niño patterns and the global warming signal in the CMIP3 GCMs is very limited, and in some cases they conflict (Guilyardi et al. 2009, Vecchi \& Wittenberg 2010). In SST projections, for example, there is no off-equatorial SST cooling under global warming (see Fig. 3 for TAS), whereas this pattern tends to occur during observed El Niño events. Under global warming, projected PR tends to increase along the equator (Fig. 5), whereas during 


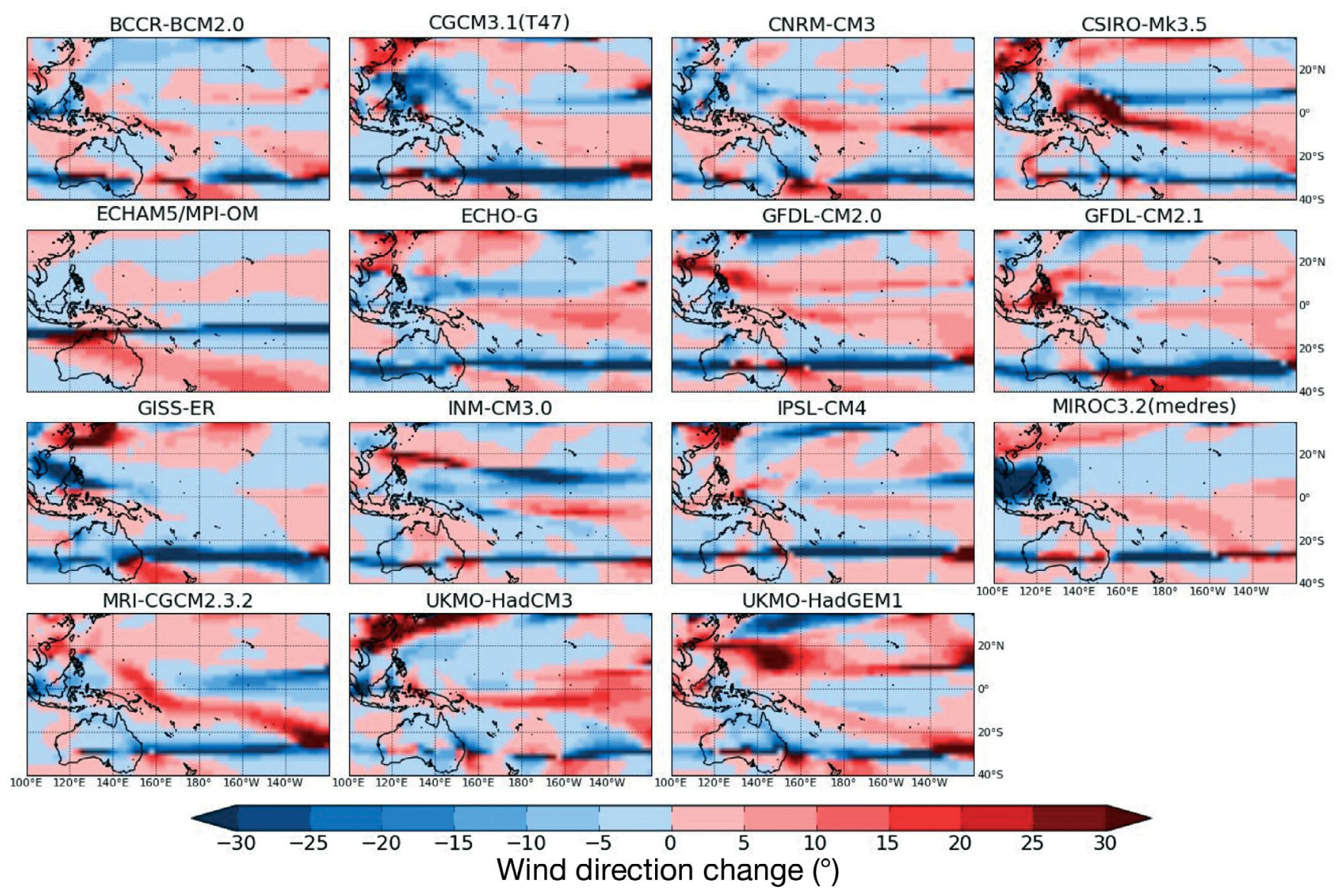

Fig. 11. Changes in wind direction (WDIR) projected by individual CMIP3 global change models (GCMs) at 2090 under the A2 scenario for May to October (MJJASO). Large changes at around $25^{\circ} \mathrm{S}$ occur in almost all models and at $10^{\circ} \mathrm{S}$ for ECHAM5/MPI-OM. Such models are simulating the boundary of the Hadley and Ferrel cells too far north, causing the anomalous wind projections for MJJASO in Figs. 7 to 10 for all 3 ensembles presented. Similar errors occurred during the November to April (NDJFMA) period; however they typically occurred around $25^{\circ} \mathrm{N}$ in most models and $10^{\circ} \mathrm{N}$ in ECHAM5/MPI-OM. See Table 1 for model descriptions

observed El Niño events there is a shift in PR maximum in the west, with PR declining in the far west but increasing further east. Mean sea level pressure (MSLP) changes (not shown) are also very different between observed El Niño events and in the simulated response to global warming. For example, during observed El Niño events the Southern Oscillation Index ( $\mathrm{SOI}_{;}$the difference in pressure between Tahiti and Darwin) decreases (Power \& Smith 2007), whereas under global warming the SOI actually increases (Power \& Kociuba 2010). This leads to wind changes under global warming (Figs. 7 \& 9) that are very different to the observed wind anomalies seen during observed El Niño.

No consistent change in ENSO behaviour and variability has emerged from climate change projections from the CMIP3 GCMs (Guilyardi et al. 2009, Collins et al. 2010, Power \& Kociuba 2010, Vecchi \& Wittenberg 2010). A number of models project a shift to- wards more El Niño events, some project a shift towards La Niña events, and others project little change from the current state (Meehl et al. 2007b, Guilyardi et al. 2009). Therefore changes in ensemble-mean PR (and TAS) cannot be attributed to ENSO changes. PR changes, especially along the equator, are therefore related to the local TAS changes and the related changes in atmospheric circulation and convergence, as discussed below.

\subsubsection{SPCZ, ITCZ and WPM}

Across the CMIP3 models there is little evidence of a systematic shift in the latitude and slope of the SPCZ ( 0 to $30^{\circ} \mathrm{S}, 155^{\circ} \mathrm{E}$ to $140^{\circ} \mathrm{W}$ ) or ITCZ ( 0 to $20^{\circ} \mathrm{N}$, $160^{\circ} \mathrm{E}$ to $120^{\circ} \mathrm{W}$ ) or the north/south east/west positions of all 3 features (austral WPM 0 to $15^{\circ} \mathrm{S}$; boreal WPM 0 to $15^{\circ} \mathrm{N}, 110^{\circ}$ to $160^{\circ} \mathrm{E}$ ) under A2 by 2090 . 
In terms of the SPCZ, the BEST ensemble mean shows no substantial shift in the zonal mean latitude or slope of the SPCZ during DJF (Fig. A1 in the Appendix), which is when the SPCZ is most intense and clearly defined. The position of the SPCZ can be calculated using a linear fit to the points of maximum precipitation in the SPCZ region, as described in Brown et al. (2011). Despite no consistent change in the position of the SPCZ, the ensemble mean annual and NDJFMA precipitation increases within the SPCZ region, as shown in Fig. 5. For all seasons and annual means, there is an increase in precipitation on and near the equator (Fig. 5), where warmer SSTs lead to an expansion of both the ITCZ and SPCZ towards the equator. There is a robust increase (of around $15 \%$ ) in the area of the DJF SPCZ when the convergence zone is defined using the $6 \mathrm{~mm} \mathrm{~d}^{-1}$ precipitation contour (Fig. A1 in the Appendix).

In terms of changes in the ITCZ position, the BEST ensemble mean shows a small displacement $\left(\sim 0.5^{\circ}\right.$; Fig. A2 in the Appendix) towards the equator in March to May (MAM) and June to August (JJA), compared to a mean location at around $8^{\circ} \mathrm{N}$. The small value of this change (below the resolution of most models) reflects both the method of its calculation (from a line 'fit' to maximum rainfall across $80^{\circ}$ of longitude) and its multi-model derivation. Although the mean change is small it reflects a strong consensus during these seasons (for example 10 models in MAM show a decrease in latitude compared with an increase in only 2; Fig. A2) and is physically consistent with increased equatorial regional rainfall. Using the 'pattern matching' method of Moise \& Delage (2011) there is found to be an increase in the area of the ITCZ (defined by the $6 \mathrm{~mm} \mathrm{~d}^{-1}$ contour) in all models during JJA and all but 3 of the CMIP3 GCMs during DJF. Increases in JJA range from close to 0 to over $30 \%$. On average, models have an expansion of around $15 \%$ by the end of the century in both DJF and JJA, corresponding to an increase of around $5 \%{ }^{\circ} \mathrm{C}^{-1}$ of Pacific warming (Fig. 3). Within this area, rates of precipitation also show general increase, resulting in models averaging a roughly $25 \%$ increase in total precipitation in JJA and $30 \%$ in DJF. This is consistent with MJJASO and NDJFMA projections in Fig. 5, although the largest fractional precipitation increases in the region are found south of the ITCZ in the climatologically dry equatorial zone.

The WPM also shows an increase in mean precipitation (not shown) during both NDJFMA (0.7 $\left.\mathrm{mm} \mathrm{d}^{-1}\right)$ and MJJASO (0.8 $\left.\mathrm{mm} \mathrm{d}^{-1}\right)$. During the austral WPM, of the 16 models simulating a change in the mean precipitation rate, 11 do so by increasing both area and peak values (the maximum PR rate within the WPM), respectively. The average increase in area is around $5 \%$ by 2090 during both the austral and boreal WPM. Four models (GFDL-CM2.0, CSIROMk3.5, ECHAM5/MPI-OM, UKMO-HadCM3) show a relatively strong increase in area and average precipitation during the boreal WPM, which does not occur during the austral WPM. These are all characterised by the ability of these models to provide reasonable simulations of ENSO events and ENSO teleconnection patterns. In summary, there is little evidence of a shift in either of the monsoon precipitation patterns, but there is evidence of an increase in both the extent and the mean precipitation rate within the patterns (not shown). This increase appears stronger in the boreal WPM and is consistent with PR projections in Fig. 5.

The projections in this paper are consistent with those of other studies (e.g. Christensen et al. 2007, Mimura et al. 2007) and when considering PR (Fig. 4) with the mean change in associated features. However, the lack of model agreement in the positioning of the features and the direction of change (Moise \& Delage 2011) and a shift in ENSO towards a more El Niño or La Niña state (Collins et al. 2010, Power \& Kociuba 2010, Vecchi \& Wittenberg 2010) hampers the explanation of changes in variables to changes in the governing drivers and features. Further research is required to increase understanding of how these features and drivers work, why the models do not agree and how the models may be improved so they are better represented. Confidently attributing changes in mean climate to changes in climate features and drivers is therefore difficult.

\subsection{Use of projections for adaptation and impacts}

Since the resolution of GCMs is very coarse (approx. $100 \times 100$ to $400 \times 500 \mathrm{~km}$ ), the information required for some adaptation and impacts planning projects (e.g. the change of species distributions relative to temperature on the island scale) may not be readily obtainable from projections like those presented here. This is not to say that projections from GCMs are redundant for every adaptation and impacts study. Indeed, many studies have employed GCM projections to determine the effects of a changing climate on many different systems, including human health and morbidity, agriculture, and ecosystem types (e.g. Luo et al. 2005, Beaumont et al. 2011). The projections presented in this study could be used 
to determine the effects of climate change on similar systems within the PCCSP domain. Furthermore, the current study has built on the projections for the region in Mimura et al. (2007) and Christensen et al. (2007) and has clarified and improved upon some of the information presented by ADB (2009). Since such information is currently being used for adaptation and impacts policy and planning, the present study may provide more detail for specific systems. We are, however, aware of the limitations of GCM projections (e.g. resolution) and by no means do we suggest that our results will be applicable to all adaptation and impacts studies, particularly those that require projections at spatial scales finer than those that GCMs can simulate.

The results in Section 4.2 suggest that caution should be exercised when selecting only one or a handful of models for projections, as unknowingly selecting models with low skill may produce unrealistic climate projections for the region analysed. Indeed small sample sizes should be avoided wherever possible, replaced by a multi-model ensemble consisting of members whose individual skill is considered fit for the purpose (Knutti 2010, Weigel et al. 2010). We therefore recommend the use of projections from the BEST ensembles rather than the WORST and ALL ensembles for risk assessment and adaptation planning across the entire PCCSP region and the feature-based regions therein.

To place the 21st century warming of the study region in a global context, Fig. 12 presents the yearly ensemble warming for the B1, A1B and A2 scenarios, averaged for the PCCSP region and the globe. By 2100 , warming over the region is $\sim 0.6^{\circ} \mathrm{C}$ less under the B1 (low emissions) scenario and $\sim 1^{\circ} \mathrm{C}$ less under the A1B (mid-range emissions) and A2 (high emissions) scenarios, compared to the global average. The annual temperature range for most of the region is generally small (between 5 and $7^{\circ} \mathrm{C}$ ) for both current and future conditions (Perkins 2011), so imposing a $\sim 1.5$ to $3^{\circ} \mathrm{C}$ warming (Fig. 11) would have much larger impacts on both the mean and extreme climate relative to a climate with a broader temperature distribution (Mearns et al. 1984). Warming trends throughout the 21st century in the Pacific are comparable to global trends in terms of the sign of the trend (Christensen et al. 2007). Fig. 12 shows that the magnitude of the trend (particularly in the latter half of the 21st century) is less than the global average.

An interesting component of projections not addressed in this study is the relation between the climate sensitivity of ensemble members and the

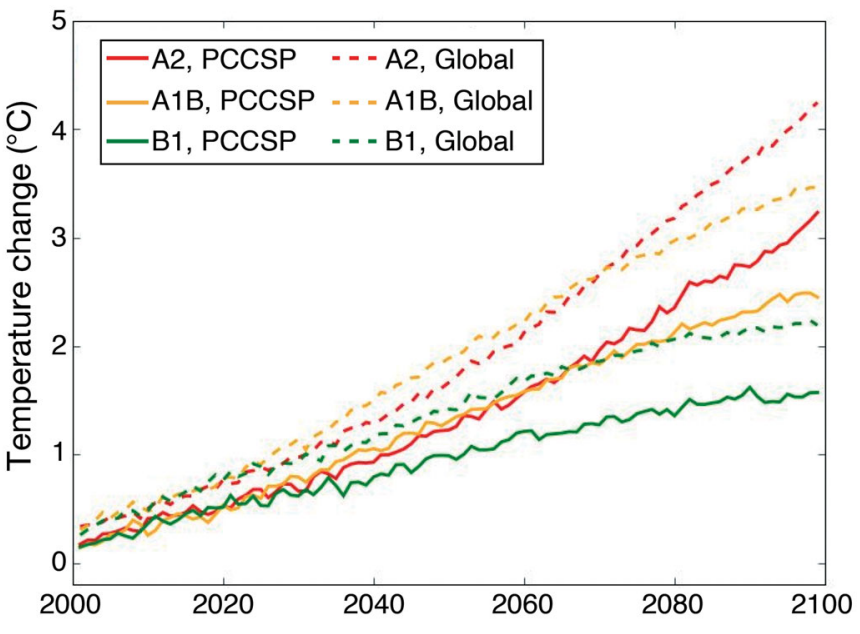

Fig. 12. Time series of surface air temperature change predicted for the 21st century using the BEST model ensemble (compared to 1990), aerially averaged for (dashed lines) the globe and (solid lines) the Pacific Climate Change Science Program (PCCSP) region for the (red) A2 high, (yellow) A1B mid-range and (green) B1 low emissions scenarios. The PCCSP region experiences less warming than the global average throughout the 21st century; however there are similarities in the patterns of warming. For example, the A2 scenario shows the most warming by 2100 , warming trends are similar among all scenarios between 2000 and 2030, and A1B shows slightly more warming by 2055

greater (smaller) warming observed in the BEST (WORST) ensemble. More specifically, determining if the amount of warming in TAS seen in each ensemble is related to the global sensitivity of the corresponding members; or member response just inherent to the region of interest. Such work would require a depth of analysis that is beyond the scope of this paper; however it is planned for future research.

Lastly, the PR projections presented are calculated as a percentage change from the baseline climate (1980-1999). Analysing PR changes as percentages were produced to be consistent with Christensen et al. (2007) and Mimura et al. (2007). The region of largest increase in Fig. 5 closely corresponds to the cold tongue in Fig. 3, which is associated with the dry zone between convergence zones. This implies that large percentage changes may be the result of increases in precipitation in the region of the dry zone, where the amount of precipitation in the baseline climatology is low. Such changes may also be influenced by model cold tongue biases (e.g Bellucci et al. 2010). Therefore, Table 6 is included to provide regionally averaged changes in PR in both percentages and the corresponding $\mathrm{mm} \mathrm{d}^{-1}$ values. The change in units does not affect the statistical significance in Section 3.2 and Table 4. 
Table 6. Regionally averaged absolute change in precipitation (PR) calculated for the ALL, BEST and WORST ensembles for annual (mm yr ${ }^{-1}$ ), November to April (mm half-yr ${ }^{-1}$; NDJFMA) and May to October (mm half-yr ${ }^{-1}$; MJJASO) projections and relative change in precipitation from the base period (1980-1999) for the same periods. Percentage change is as presented in Fig. 5. All values are rounded to the nearest integer. See Table 2 for region abbreviations and locations

\begin{tabular}{|c|c|c|c|c|c|c|c|c|c|}
\hline \multirow[t]{2}{*}{ Region } & \multicolumn{3}{|c|}{$\longrightarrow$ ALL } & \multicolumn{3}{|c|}{$\longrightarrow \mathrm{BEST}-$} & \multicolumn{3}{|c|}{ WORST } \\
\hline & Annual & NDJFMA & MJJASO & Annual & NDJFMA & MAJJASO & Annual & NDJFMA & MAJJASO \\
\hline \multicolumn{10}{|c|}{ Absolute change $(\mathrm{mm})$} \\
\hline PCCSP & 177 & 90 & 87 & 185 & 96 & 90 & 146 & 68 & 78 \\
\hline WPM & 185 & 94 & 93 & 190 & 99 & 93 & 168 & 76 & 93 \\
\hline ITCZ & 190 & 69 & 120 & 210 & 75 & 135 & 111 & 49 & 66 \\
\hline SPCZ & 192 & 111 & 80 & 201 & 121 & 81 & 158 & 77 & 80 \\
\hline \multicolumn{10}{|c|}{ Relative change (\%) } \\
\hline PCCSP & 15 & 15 & 18 & 16 & 16 & 19 & 12 & 11 & 17 \\
\hline WPM & 8 & 9 & 7 & 8 & 10 & 7 & 7 & 5 & 8 \\
\hline ITCZ & 14 & 19 & 35 & 26 & 38 & 22 & 14 & 10 & 27 \\
\hline SPCZ & 17 & 19 & 18 & 17 & 20 & 19 & 16 & 17 & 17 \\
\hline
\end{tabular}

\section{CONCLUSIONS}

Overall, changes in surface air temperature (TAS) and precipitation (PR) over the study region (Fig. 1) are similar to the projections presented in Christensen et al. (2007) and Mimura et al. (2007) for the Pacific region. This is to be expected at least to some degree, given that the projections are based mostly on the same GCMs. However, projections presented by Christensen et al. (2007) and Mimura et al. (2007) are a summary across a wider domain, with no exploration into the performance or spread of the models. This paper has presented additional information not provided by Mimura et al. (2007) and Christensen et al. (2007), including:

(1) projections from GCMs with a Pacific-based focus, highlighting spatial and scenario-dependant differences;

(2) the separation of ensemble members based on model skill, and the comparison of the respective mean projections to that of the ALL ensemble (the same all-model ensemble use used in Christensen et al. 2007 and Mimura et al. 2007);

(3) a measure of uncertainty (standard deviation) among members for each of the 3 ensembles analysed (ALL, BEST, WORST);

(4) projections in wind speed (WSP) and wind direction (WDIR); and

(5) mean feature-based regional changes as well as the mean feature-based regional differences between the BEST and WORST ensemble subsets relative to the ALL ensemble.

Uncertainty (in terms of ensemble member agreement) has also been quantified, relationships to key drivers and features have been discussed, and the regional warming has been compared with global warming. In summary this study has found:

(1) Over the PCCSP region, surface air temperature increases, precipitation generally increases especially over the equator, wind speed increases and decreases in the south and north, respectively, and wind direction tends to more easterly flows;

(2) Models with less skill in simulating baseline conditions exhibit significant biases relative to the ALL ensemble, where projections are spatially averaged at the regional (i.e. PCCSP domain) and subregional (i.e. WPM-, ITCZ-, and SPCZ-influenced areas) scale. This result is consistent across annual and 6-monthly projections (Tables 2 to 5);

(3) Uncertainty (as defined by model consensus) is decreased in some cases for PR, WSP and WDIR, and in all cases for TAS when eliminating models with less skill;

(4) As the large-scale climate features such as the ITCZ, SPCZ and the WPM strongly influence mean and seasonal precipitation and atmospheric circulation, changes in these variables are likely to be associated with changes in the climate features. However, disagreement between models about the position and projected change in the climate features makes explaining ensemble mean changes in terms of these features difficult; and

(5) Eliminating GCMs that less skilfully simulate the regional climate (Irving et al. 2011) does not reduce all uncertainty from projections (e.g. Jun et al. 2008, Knutti 2010) but does provide ensemble projections that are considered more plausible. Differences between projections based on the models retained 
(BEST) and projections using all models (ALL) are generally statistically significantly different, especially for TAS.

These results and associated projections may prove valuable to those requiring more detail than that presented in the IPCC AR4. Mimura et al. (2007) state that regional climate models (RCMs) are essential for providing quantitative climate projections for the $\mathrm{Pa}$ cific Island nations. However, due to computation and time restraints, RCMs are generally only driven for a subset of CMIP3 GCMs and generally for just one emission scenario (e.g. Christensen \& Christensen 2007, Kjellström et al. 2007). Futhermore, running simulations forced by every GCM projection available is not practical, especially for numerous RCMs. Whilst RCM projections may provide an extra level of valuable information, such results would represent a finer resolution sub-sample of the broader range of uncertainty. RCM projections should therefore be interpreted alongside the GCM projections. Lastly, since GCMs are unavoidably used to force future RCM projections, results from the present study combined with recommendations made by Irving et al. (2011) may influence which GCMs are chosen for downscaling by RCMs over the PCCSP region.

Acknowledgements. The research discussed in this paper was conducted with the support of the Pacific Climate Change Science Program (PCCSP), a program supported by AusAID, in collaboration with the Department of Climate Change and Energy Efficiency and delivered by the Bureau of Meteorology and the Commonwealth Scientific and Industrial Research Organisation (CSIRO). We acknowledge the modeling groups, the Program for Climate Model Diagnosis and Intercomparison (PCMDI) and the World Climate Research Program's Working Group on Coupled Modelling for their roles in making available the CMIP3 multi-model dataset. Support of this dataset was provided by the Office of Science, U.S. Department of Energy. More details on model documentation are available at the PCMDI website (www-pcmdi.llnl.gov). We also thank J. Richmond for drafting the map shown in Fig. 1 and K. Hennessy, P. Whetton and B. Murphy for providing invaluable feedback.

\section{LITERATURE CITED}

ADB (Asian Development Bank) (2009) Mainstreaming climate change in ADB operations, climate change implementation plan for the Pacific (2009-2015). Mandaluyong City, Philippines

Ashok K, Behera SK, Rao SA, Weng H, Yamagata T (2007) El Niño Modoki and its possible teleconnection. J Geophys Res 112:C11007, doi:10.1029/2006JC003798

Beaumont LJ, Pitman A, Perkins S, Zimmermann NE, Yoccoz NG, Thuiller W (2011) Impacts of climate change on the world's most exceptional ecoregions. Proc Natl Acad Sci USA 108:2306-2311
Bellucci A, Gualdi S, Navarra A (2010) The double-ITCZ syndrome in coupled general circulation models: the role of large-scale vertical circulation regimes. J Clim 23: 1127-1145

> Brown JR, Power SB, Delage FB, Colman RA, Moise AF, Murphy BF (2011) Evaluation of the South Pacific Convergence Zone in IPCC AR4 climate model simulations of the twentieth century. J Clim 24:1565-1582

Collins M, An SI, Cai W, Ganachaud A and others (2010) The impact of global warming on the tropical Pacific Ocean and El Niño. Nat Geosci 3:391-397

Covey C, Gleckler PJ, Phillips TJ, Bader DC (2006) Secular trends and climate drift in coupled ocean-atmosphere general circulation models. J Geophys Res 111:D03107, doi:10.1029/2005JD006009

Christensen JH, Christensen OB (2007) A summary of the PRUDENCE model projections of changes in European climate by the end of this century. Clim Change 81:7-30

Christensen JH, Hewitson B, Busuioc A, Chen A and others (2007) Regional climate projections. In: Solomon S, Qin $\mathrm{D}$, Manning $\mathrm{M}$, Chen Z and others (eds) Climate change 2007: the physical science base. Contribution of Working Group I to the Fourth Assessment Report of the Intergovernmental Panel on Climate Change. Cambridge University Press, Cambridge, p 847-940

Dessai S, Lu X, Hulme M (2005) Limited sensitivity analysis of regional climate change probabilities for the 21st century. J Geophys Res 110:D19108, doi:10.1029/2005JD 005919

Diaz HF, Markgraf V (2000) El Niño and the Southern Oscillation: multiscale variability and global and regional impacts. Cambridge University Press, Cambridge

> Folland CK, Renwick JA, Salinger MA, Mullan AB (2002) Relative influences of the Interdecadal Pacific Oscillation and ENSO on the South Pacific Convergence Zone. Geophys Res Lett 29:1643, doi:10.1029/2001GL014201

> Giorgi F, Mearns LO (2002) Calculation of average, uncertainty range, and reliability of regional climate changes from AOGCM simulations via the 'reliability ensemble averaging' (REA) method. J Clim 15:1141-1158

- Giorgi F, Mearns LO (2003) Probability of regional climate change based on the reliability ensemble averaging (REA) method. Geophys Res Lett 30:1629, doi:10.1029/ 2003GL017130

> Gleckler PJ, Taylor KE, Doutriaux C (2008) Performance metrics for climate models. J Geophys Res 113:D06104 doi:10.1029/2007JD008972

- Guilyardi E, Wittenberg A, Fedorov A, Collins M and others (2009) Understanding El Niño in ocean-atmosphere general circulation models: progress and challenges. Bull Am Meteorol Soc 90:325-340

> Hendon HH, Liebmann B (1990a) A composite study of onset of the Australian summer monsoon. J Atmos Sci 47: 2227-2240

> Hendon HH, Liebmann B (1990b) The intraseasonal (30-50 day) oscillation of the Australian summer monsoon. J Atmos Sci 47:2909-2923

> Irving DB, Perkins SE, Brown JR, Sen Gupta A and others (2011) Evaluating global climate models for the Pacific island region. Clim Res 49:169-187

Jun M, Knutti R, Nychka DW (2008) Spatial analysis to quantify numerical model bias and dependence. J Am Stat Assoc 103:934-947

Kjellström E, Bärring L, Jacob D, Jones R, Lenderink G, Schär C (2007) Modelling daily temperature extremes: 
recent climate and future changes over Europe. Clim Change 81:249-265

Knutti R (2010) The end of model democracy? Clim Change 102:395-404

Knutti R, Abramowitz G, Collins M, Eyring V, Gleckler PJ, Hewitson B, Mearns L (2010) Good practice guidance paper on assessing and combining multi model climate projections. In: Stocker TF, Qin D, Plattner GK, Tignor M, Midgley PM (eds) Meeting report of the Intergovernmental Panel on Climate Change expert meeting on assessing and combining multi model climate projections. IPCC Working Group I Technical Support Unit, University of Bern, Bern, p 1-13

Liu Y, Guo L, Wu G, Wang Z (2010) Sensitivity of ITCZ configuration to cumulus convective parameterizations on an aqua planet. Clim Dyn 34:223-240

> Lowe JA, Gregory JM (2010) A sea of uncertainty. How well can we predict future sea level rise? Nature Rep Clim Change 4:42-43

> Luo Q, Jones RN, Williams M, Bryan B, Bellotti W (2005) Probabilistic distributions of regional climate change and their application in risk analysis of wheat production. Clim Res 29:41-52

Mearns LO, Katz RW, Schneider SH (1984) Extreme hightemperature events: changes in their probabilities with changes in mean temperature. J Appl Meteorol 23: 1601-1613

> Meehl GA, Covey C, Taylor KE, Delworth T and others (2007a) The WCRP CMIP3 multimodel dataset: a new era in climate change research. Bull Am Meteorol Soc 88: 1383-1394

Meehl GA, Stocker TF, Collins WD, Friedlingstein P and others (2007b) Global climate projections. In: Solomon S, Qin D, Manning M, Chen Z and others (eds) Climate change 2007: the physical science basis. Contribution of Working Group I to the Fourth Assessment Report on the Intergovernmental Panel on Climate Change. Cambridge University Press, Cambridge p 747-845

Mimura N, Nurse L, McLean RF, Agard J and others (2007) Small islands. In: Parry ML, Canziani OF, Palutikof JP, van der Linden PJ, Hanson CE (eds) Climate change 2007: impacts, adaptation and vulnerability. Contribution of Working Group II to the Fourth Assessment Report of the Intergovernmental Panel on Climate Change. Cambridge University Press, Cambridge, p 687-716

> Moise AF, Delage FP (2011) New climate model metrics based on object-orientated pattern matching of precipitation. J Geophys Res 116:D12108, doi:10.1029/2010JD 015318

Murphy JM, Sexton DMH, Barnett DN, Jones GS, Webb MJ, Collins M, Stainforth DA (2004) Quantification of modelling uncertainties in a large ensemble of climate change simulations. Nature 430:768-772

Nakićenović N, Alcamo J, Davis G, de Vries B and others (2000) IPCC special report on emission scenarios. Cambridge University Press, Cambridge

> Nunn PD (2009) Responding to the challenges of climate change in the Pacific islands: management and technological imperatives. Clim Res 40:211-231

Perkins SE (2011) Biases and model agreement in projections of climate extremes over the tropical Pacific. Earth Interact 15:1-36

Perkins SE, Pitman AJ, Holbrook NJ, McAneney J (2007) Evaluation of the AR4 climate models' simulated daily maximum temperature, minimum temperature and pre- cipitation over Australia using probability density functions. J Clim 20:4356-4376

Perkins SE, Pitman AJ (2009) Do weak AR4 models bias projections of future climate changes over Australia? Clim Change 93:527-558

Perkins SE, Pitman AJ, Sisson SA (2009) Smaller projected increases in 20-year temperature returns over Australia in skill-selected climate models. Geophys Res Lett 36: L06710, doi:10.1029/2009GL037293

> Piani C, Frame DJ, Stainforth DA, Allen MR (2005) Constraints on climate change from a multi-thousand member ensemble of simulations. Geophys Res Lett 32: L23825, doi:10.1029/2005GL024452

Pierce DW, Barnett TP, Santer BD, Gleckler PJ (2009) Selecting global climate models for regional climate change studies. Proc Natl Acad Sci USA 106:8441-8446

Pitman AJ, Perkins SE (2008) Regional projections of future seasonal and annual changes in precipitation and temperature over Australia based on skill-selected AR4 models. Earth Interact 12:1-50

Power SB (1995) Climate drift in a global ocean general circulation model. J Phys Oceanogr 25:1025-1036

Power SB, Kociuba G (2011) The impact of global warming on the Southern Oscillation Index. Clim Dyn 37: 1745-1754

> Power SB, Smith IN (2007) Weakening of the Walker Circulation and apparent dominance of El Niño both reach record levels, but has ENSO really changed? Geophys Res Lett 34:L18702, doi:10.1029/2007GL030854

> Räisänen J (2007) How reliable are climate models? Tellus 59:2-29

Reifen C, Toumi R (2009) Climate projections: past performance no guarantee of future skill? Geophys Res Lett 36: L13704, doi:10.1029/2009GL038082

Sánchez E, Romera R, Gaertner MA, Gallardo C, Castro M (2009) A weighting proposal for an ensemble of regional climate models over Europe driven by 1961-2000 ERA40 based on monthly precipitation probability density functions. Atmos Sci Lett 10:241-248

Santer BD, Taylor KE, Gleckler PJ, Bonfils C and others (2009) Incorporating model quality information in climate change detection and attribution studies. Proc Natl Acad Sci USA 106:14778-14783

Schneider SH, Rosencranz A, Niles JO (eds) (2002) Climate change policy: a survey. Island Press, Washington, DC

Sen Gupta A, Muir LC, Brown JN, Phipps SJ, Durack PJ, Monselesan D, Wijffels SE (in press) Climate drift in the CMIP3 models. J Clim

Smith I, Chandler E (2010) Refining precipitation projections for the Murray Darling Basin of south-east Australiathe effect of sampling model results based on performance. Clim Change 102:377-393

> Stainforth DA, Allen MR, Tredger ER, Smith LA (2007) Confidence, uncertainty and decision-support relevance in climate predictions. Philos Trans R Soc Lond A 365: 2145-2161

Stephens MA (1970) Use of the Kolmogorov-Smirnov, Cramér-Von Mises and related statistics without extensive tables. J R Stat Soc B 32:115-122

Stephens MA (1986) Tests based on EDF statistics. In: D'Agostino RB, Stephens MA (eds) Goodness-of-fit techniques. Marcel Dekker, New York, NY

Taylor KE (2001) Summarizing multiple aspects of model performance in a single diagram. J Geophys Res 106: 7183-7192, doi:10.1029/2000JD900719 
Tebaldi C, Hayhoe K, Arblaster JM, Meehl GA (2006) Going to the extremes, an intercomparison of model-simulated historical and future changes in extremes events. Clim Change 79:185-211

Tebaldi C, Knutti R (2007) The use of the multi-model ensemble in probabilistic climate projections. Philos Trans R Soc Lond A 365:2053-2075

van Oldenborgh GJ, Philip SY, Collins M (2005) El Niño in a changing climate: a multi-model study. Ocean Sci 1:81-95

$>$ Vecchi GA, Wittenberg AT (2010) El Niño and our future climate: Where do we stand? Wiley Interdiscip Rev Clim Change 1:260-270

Vecchi GA, Soden BJ, Wittenberg AT, Held IM, Leetmaa A, Harrison MJ (2006) Weakening of tropical Pacific atmospheric circulation due to anthropogenic forcing. Nature 441:73-76

Vincent DG (1994) The South Pacific Convergence Zone (SPCZ): a review. Mon Weather Rev 122:1949-1970

Waliser DE, Gautier C (1993) A satellite-derived climatology of the ITCZ. J Clim 6:2162-2174

Weigel AP, Knutti R, Liniger MA, Appenzeller C (2010) Risks of model weighting in multimodel climate projections. J Clim 23:4175-4191

Whetton P, Macadam I, Bathols J, O'Grady J (2007) Assessment of the use of current climate patterns to evaluate regional enhanced greenhouse response patterns of climate models. Geophys Res Lett 34:L14701, doi:10.1029/ 2007GL030025

Xu Y, Gao X, Giorgi F (2010) Upgrades to the reliability ensemble averaging method for producing probabilistic climate-change projections. Clim Res 41:61-81

Zhang GJ, Song X (2010) Convection parameterization, tropical Pacific double ITCZ, and upper-ocean biases in the NCAR CCSM3. Part II: coupled feedback and the role of ocean heat transport. J Clim 23:800-812

Zhun Y, Chen L (2002) The relationship between the Asian/Australian monsoon and ENSO on a quasi-fouryear scale. Adv Atmos Sci 19:727-740 


\section{Appendix.}

Changes in the position of the South Pacific Convergence Zone (SPCZ) and the Intertropical Convergence Zone (ITCZ), projected by the CMIP3 models Under the A2 scenario for the period 2080-2099

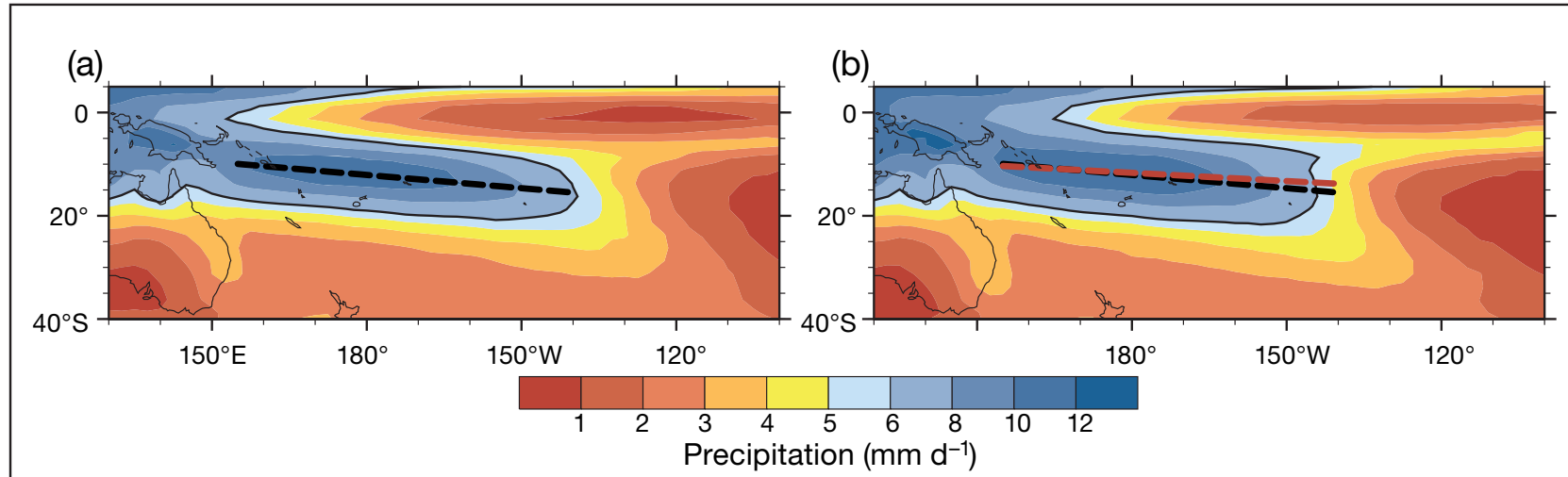

Fig. A1. Mean seasonal mean precipitation $\left(\mathrm{mm} \mathrm{d}^{-1}\right)$ relative to the position of the South Pacific Convergence Zone (SPCZ) (a) recorded during the 20th century (1980-1999) and (b) predicted for the 21st century (2080-2099) for a high (A2) emissions scenario using the December to February (DJF) BEST model ensemble. (black dashed line) 20th century SPCZ position, (red dashed line) 21st century A2 SPCZ position. The SPCZ position is calculated by fitting a line to the latitudes of maximum precipitation within the longitude range $155^{\circ} \mathrm{E}$ to $140^{\circ} \mathrm{W}$ (see Brown et al. 2011 for details)
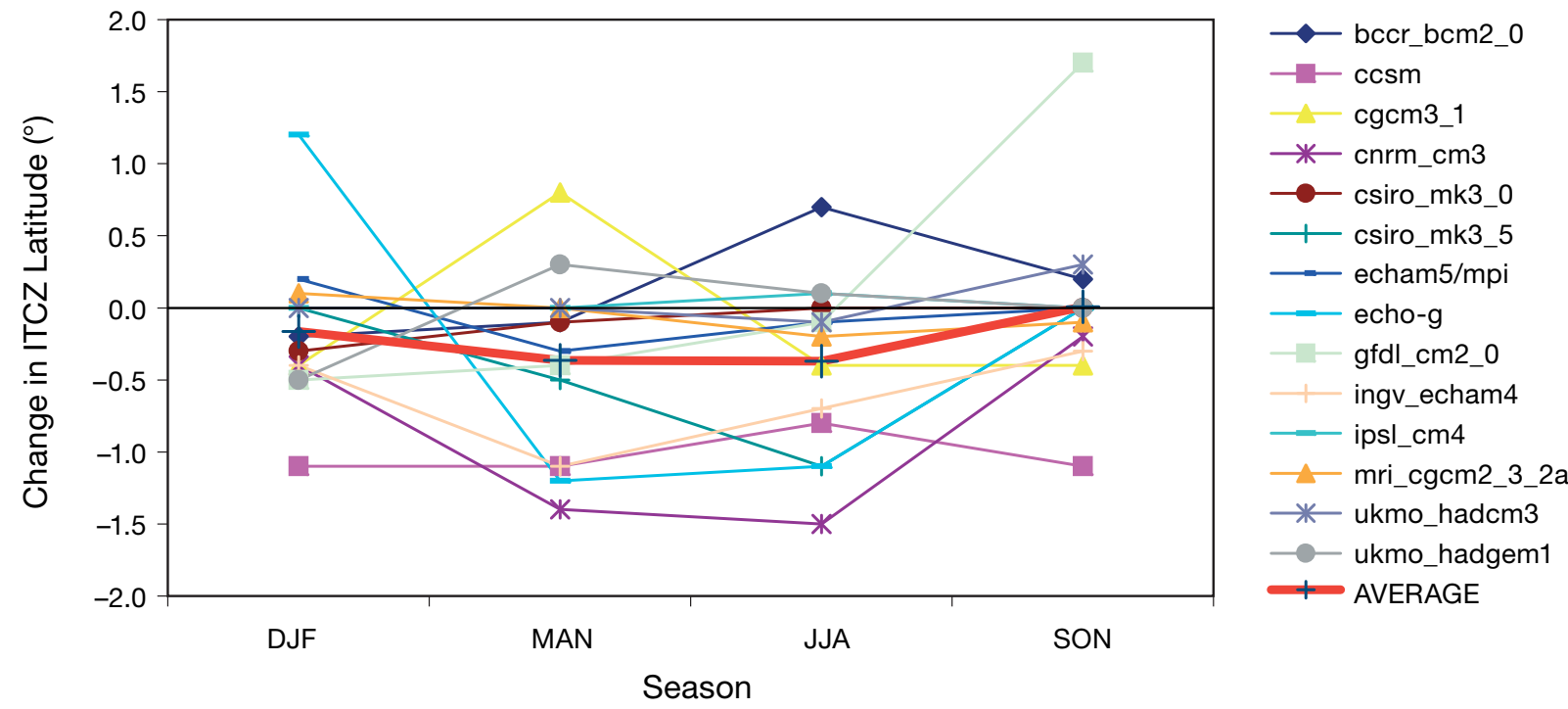

Fig. A2. Change in the Intertropical Convergence Zone (ITCZ) latitude for individual models of the BEST ensemble as well as the ensemble average across 4 seasons (DJF: December to February. MAM: March to May. JJA: June to August. SON: September to November). While results from different ensemble models vary, the ensemble average change is a $\sim 0.5^{\circ}$ shift towards the south. See Table 1 for model descriptions

Editorial responsibility: Filippo Giorgi, Trieste, Italy
Submitted: January 28, 2011; Accepted: August 26, 2011 Proofs received from author(s): January 11, 2012 